\title{
La Corona, los moriscos granadinos y el servicio de 1603. Pacto fiscal y negociación política
}

\author{
The Crown, the Moriscos of Granada and \\ the Servicio of 1603. \\ Fiscal Pact and Political Negotiation
}

\author{
Francisco J. Moreno Díaz del Campo \\ Universidad de Castilla-La Mancha \\ orcid.org/0000-0001-7929-5080
}

El artículo analiza los pormenores que rodearon la negociación y recaudación del servicio fiscal de 1603, el último de los tres que los moriscos granadinos entregaron a la Corona tras su establecimiento en Castilla con posterioridad a la Guerra de las Alpujarras.

Para su redacción se ha hecho uso de documentación conservada en el Archivo General de Simancas, aunque también se ha recurrido a informaciones procedentes de archivos de protocolos y municipales.

Entre sus principales aportaciones caben destacar tres aspectos: da a conocer el contenido de las cláusulas que conformaron el asiento final firmado entre moriscos y Corona; contribuye a establecer una geografía precisa de las aljamas implicadas en el pago del impuesto y, finalmente, proporciona cifras concretas en torno a las cantidades comprometidas por cada comunidad.

Junto a ello, se analizan las irregularidades, problemas y situaciones experimentadas en servicios anteriores, aspectos ya conocidos pero que, vistos en relación al texto del acuerdo de 1603, permiten observar cómo condicionaron la negociación y sirvieron para perfilar y perfeccionar el articulado del contrato final suscrito entre la minoría y el monarca.

Palabras clave: moriscos, fiscalidad, servicio, Castilla, 1603
This paper analyses the details that characterized the negotiation and collection of the servicio de los naturales (a tax also named "donativo") from the year 1603 onwards, the last time of those three in which moriscos of Granada paid to the Hispanic Monarchy after the Alpujarras War, when they were settled in Castile.

The author has analysed documents coming from the Archivo General de Simancas, but also those included in notary's protocols and in local archives.

Its main contributions are three: to publish the content of the actual contract signed by the moriscos and the Crown; to contribute to set up a precise spatial distribution of the communities that paid the tax and, finally, to show the amounts delivered by them.

Irregularities, problems, and conflicts lived while the precedent servicios were being paid, are analysed too. There are aspects that we know thanks to other previous works. Nevertheless, if they are considered in relation with the situation of the year 1603, they allow observing that all those difficulties were used in order to improve the servicio itself and the agreement between the minority and the King.

Key words: moriscos, taxation system, tax, Castile, 1603

Copyright: (C) 2017 CSIC. Este es un artículo de acceso abierto distribuido bajo los términos de la licencia de uso y distribución Creative Commons Attribution (CC-by) España 3.0. 
Se suele hacer referencia a los años setenta del siglo XVI para referirse a la etapa, todavía mal conocida, en la que se inició el proceso de reconstrucción de las comunidades de granadinos en el exilio. Se trata de un fenómeno solo esbozado, trazado aún con pincel grueso para el conjunto de Castilla, pero del cual se va conociendo cada vez más. Gracias a los avances producidos comienza a saberse que, lejos de suponer una década inerte, los dos lustros que siguieron a la guerra de las Alpujarras sirvieron para que los vencidos erigieran en Castilla un nuevo armazón de relaciones productivas y sociales cuya plasmación más evidente fue la reactivación económica del grupo. De manera paralela, las elites granadinas afincadas en el interior de la península Ibérica se entregaron a la causa de tejer nuevos hilos de comunicación con la Monarquía. Esa "reconstrucción institucional en el exilio"1 puede darse por totalmente armada a principios de los años 1590 , cuando, sobre la base del pacto fiscal, tomó cuerpo la idea de fijar por escrito las condiciones a que los moriscos se someterían en su intento de llegar a una entente con el rey, logrando así fijar un esquema de relaciones casi paralelo al existente en Granada antes de la guerra ${ }^{2}$. Dicha situación comenzó a hacerse visible a partir del momento en el que ambas partes iniciaron las negociaciones que concluyeron con la concesión del servicio de $1591^{3}$, que se sepa, el primero de los tres que los granadinos entregaron a los monarcas hispanos con posterioridad a $1570^{4}$. Por parte morisca, tuvieron como protagonistas a algunos de los más destacados representantes de la elite en el exilio ${ }^{5}$ y se materializaron en el inicio de toda una serie de negociaciones en las que, dinero de por medio, el objetivo principal fue lograr el compromiso regio de dispensar un mejor trato a los propios moriscos, e, incluso, de autorizar

\footnotetext{
${ }^{1}$ Según la acertada expresión de Pérez García y Fernández Chaves en Las elites moriscas entre Granada y el Reino de Sevilla, p. 151.

${ }^{2}$ Pérez García y Fernández Chaves, Las elites moriscas entre Granada y el Reino de Sevilla, p. 154.

${ }^{3}$ Para las negociaciones políticas de los granadinos y su ligazón con la concesión de los servicios constituye un imprescindible punto de partida el trabajo del profesor Vincent, "Los moriscos granadinos".

${ }^{4}$ Los servicios fiscales de los naturales del reino de Granada se hicieron efectivos en 1591,1597 y 1603 , los dos primeros por valor de 200000 ducados y un periodo de cuatro años, y el último por 240000 ducados pero en ocho anualidades.

${ }^{5}$ Vincent, "Los moriscos granadinos", p. 167. Junto al anterior, resultan de obligada consulta la aportación del propio Vincent, "Les frères Berrio" y el interesante artículo de Pérez García y Fernández Chaves, "Los hermanos Berrio: capital morisco".
} 
el regreso de parte de los exiliados a tierras granadinas, anhelo que pronto se mostró como inalcanzable.

El funcionamiento y estructura de tales contribuciones son de sobra conocidos gracias al exhaustivo análisis que publicó en su día el profesor Juan Jesús Bravo Caro ${ }^{6}$ si bien es cierto que el contexto político a que dieron lugar las conversaciones está aún por definir. Con todo, parece claro que la negociación y el pago de los servicios de los naturales del reino de Granada tienen dos puntos de anclaje: de una parte, y tal y como apunta el profesor Vincent, el regreso a Granada, siempre presente entre las reivindicaciones moriscas; de otra, el contexto de bancarrota vivido por la Monarquía Hispánica en el tramo final del XVI, algo de lo que se hizo eco en su día don Modesto Ulloa ${ }^{7}$. Por ello, es fácil comprender que el establecimiento definitivo del "gracioso donativo" respondiera al resultado último de un pacto, "de un acuerdo entre Rey y moriscos", y que, en dicha línea, no suponga sino una mera continuación de aquellos otros "contratos fiscales" a los que ya habían llegado ambos interlocutores con anterioridad a la Guerra de las Alpujarras?.

\footnotetext{
${ }^{6}$ Bravo Caro, "Un impuesto de desterrados". Son igualmente interesantes las referencias que, a escala local, pueden encontrarse en Magán García y Sánchez González, Moriscos granadinos en La Sagra de Toledo, p. 67; Aranda Doncel, Los moriscos en tierras de Córdoba, pp. 240-246; y García López, Moriscos en tierras de Uceda y Guadalajara, pp. 126-127 y Señores, seda y marginados. La comunidad morisca en Pastrana, pp. 143-150.

${ }^{7}$ Vincent, "Los moriscos granadinos", pp. 170-171; Ulloa, La hacienda real de Castilla en el reinado de Felipe II, pp. 332-333. En ese mismo contexto de dificultades financieras es donde cabe encuadrar el servicio (casi paralelo al analizado aquí) que los moriscos del reino de Valencia comprometieron por las mismas fechas ante Felipe III. De su existencia dio cuenta Henri Lapeyre (pp. 18-19 y 22) para señalar los listados de contribuyentes como una de las fuentes disponibles para estudiar la demografía morisca valenciana a inicios del XVII. También T. Halperin Donghi (pp. 47 y 167) lo menciona y da la cifra de 60000 libras como el final comprometido por parte morisca. Sus referencias fueron completadas por María Luïsa Muñoz i Altabert, quien inserta el donativo morisco en el más amplio y general que el reino de Valencia ofreció al monarca en 1602. A raíz de sus investigaciones, se sabe que la cantidad ofrecida por parte morisca fue tan solo una parte de las más de 387000 libras que ofreció el reino. No obstante y, como indica la propia autora, aún son desconocidos "los criterios que fueron utilizados para fijar esta cantidad". Véase Muñoz i Altabert, "El servi de 1602", pp. 125-136. De la misma autora, en Les Corts valencianes de Felipe III, pp. 31-44.

${ }^{8}$ Llama poderosamente la atención la igualdad en el empleo de ambos términos tanto en el servicio de los granadinos como en el otorgado por los propios valencianos. Véase Muñoz i Altabert, "El servei de 1602”, p. 126.

${ }^{9}$ Para comprender la fiscalidad del antiguo reino nazarí son de obligada consulta el capítulo referente a "La Hacienda" incluido en la Historia del Reino de Granada, así como Galán Sánchez y Peinado Santaella, Hacienda regia y población en el Reino de Granada
} 


\section{Lo que por nuestro mandado se asienta (...) acudiendo a la obligación de tan buenos vasallos. Disposiciones y acuerdos del servicio de 1603.}

Todo parece indicar que el pacto político que precedió al pago de los distintos servicios moriscos sirvió, en cada ocasión, para renovar las cláusulas a que cada parte quedó sometida mediante el establecimiento del "contrato" final firmado entre rey y nación morisca. También que el nivel de exigencia de los moriscos se vio reducido con el paso del tiempo. Las aspiraciones moriscas previas a la concesión del servicio de 1603 son conocidas gracias a la respuesta que, a petición del duque de Lerma, ofreció la junta constituida para aconsejar al monarca acerca de los derroteros por los que debían orientarse las negociaciones con la minoría ${ }^{10}$. A resultas de las cuestiones planteadas por el valido, la comisión (conformada por el confesor regio, por don Pedro Franquiza y por un tal licenciado Ramírez) informó al Consejo de Hacienda de las peticiones contenidas en el memorial remitido por los moriscos, quienes, ya por entonces, aceptaban "incluso el no volver al Reino de Granada sin licencia regia"11, cuestión planteada como irrenunciable punto de partida tan solo unos años antes. En esencia, lo único que se deduce de dicho documento es que, a la altura de 1602, los moriscos sólo reclamaban del rey que la Corona asegurase un buen y correcto tratamiento y que el cumplimiento de esa premisa se tradujese en el respeto a sus personas y bienes y en que se evitase cualquier tipo de trato vejatorio a la hora de considerarlos "como christianos viejos, sin hazer distinçión dellos (...) y que no consientan que nadie les llame, moros, ni moriscos ni otros nombres de oprobrio", reivindicación ésta que, por cierto, siempre había estado presente en las peticiones elevadas al monarca por las comunidades moriscas asentadas en Castilla, tanto en las procedentes de los antiguos grupos mudéjares como, posteriormente, en las de los exiliados granadinos ${ }^{12}$.

y el ya clásico trabajo de B. Vincent sobre "Las rentas particulares del reino de Granada en el siglo XVI". Para una mayor concreción en torno al asunto del servicio debe recurrirse a los trabajos de Galán Sánchez, "La consolidación de una fiscalidad diferencial"; "«Herejes consentidos»: la justificación" y "El dinero del rey y la «ley de la comunidad»". Finalmente debe destacarse también la aportación de García Pedraza acerca de "Los cogedores de los servicios moriscos del reino de Granada".

${ }^{10}$ Bravo Caro, "Un impuesto de desterrados", p. 52.

${ }^{11}$ Bravo Caro, "Un impuesto de desterrados", p. 52.

${ }^{12}$ García López, "Conflictividad y conciencia”, p. 466. 
No obstante, las condiciones finales fueron algo más allá ${ }^{13}$. Las negociaciones que desembocaron en la rúbrica del acuerdo se fraguaron en paralelo al pago del servicio anterior. De hecho, fue precisamente esta coyuntura la que, según parece, pudo contribuir a pulir los defectos detectados como consecuencia de su gestión y a trasladar al texto del nuevo "contrato" las cláusulas y especificaciones que terminaron por mejorarlo. El asiento del servicio se firmó en Valladolid el siete de noviembre de 1602 y su contenido se distribuye en dieciocho cláusulas que pueden agruparse en tres grandes bloques: en primer lugar aquellas que se encargaron de delimitar quiénes estaban obligados a contribuir $\left(\mathrm{n}^{\mathrm{os}} 7,8\right.$ y 9); junto a ellas, las que fijaron las contraprestaciones obtenidas por la minoría ( $\mathrm{n}^{\mathrm{os}} 1$ a 6$)$; finalmente ( $\mathrm{n}^{\mathrm{os}} 10$ a 17) aquellas otras que se ocuparon de dar forma a la gestión del propio "donativo" así como de establecer las competencias que debía asumir cada parte durante el tiempo en que se extendiera el propio servicio y en todo lo tocante al mismo. A ellas cabría añadir la disposición final ( $\left.\mathrm{n}^{\mathrm{o}} 18\right)$, que, en realidad, es la primera que cabría analizar porque en ella se estableció el montante total "donado" por los moriscos (240000 ducados) y los plazos de entrega (ocho años) así como el compromiso regio de que todo lo acordado sería, en adelante, de obligado cumplimiento y de que su no acatamiento supondría la revocación automática del acuerdo.

Como ha quedado dicho, las cláusulas séptima a novena delimitaron quiénes estaban comprendidos en la obligación de pagar el servicio. En ese sentido, las disposiciones resultaron claras y tajantes al incluir a "todos los naturales del dicho Reyno de Granada, Mudégares y Gazis, que están en estos nuestros Reynos" ${ }^{14}$. La precisión no era baladí; de hecho, como ha demostrado recientemente Manuel Fernández Chaves, la inclusión de los gazis ya había despertado suspicacias y más de un encontronazo con motivo de la recaudación de los servicios anterio-

${ }^{13}$ Como indica García Ruipérez en "La expulsión de los moriscos" (p. 91, nota 34), su contenido es conocido por haberse conservado copia impresa del mismo como parte de una causa criminal vista a finales de 1608 en contra de un morisco de Los Yébenes que había violado su lista de vecindad. Archivo Municipal de Toledo (en adelante AMT), sig. 6420. Vaya desde aquí nuestro agradecimiento al autor por la desinteresada cesión de dicho documento.

${ }^{14}$ AMT, sig. 6420, fol. 38r. 
res $^{15}$. En ese sentido, como indica Bravo Caro, la recaudación del servicio debía tomar como referencia "las líneas maestras del sistema seguido en los Millones"16; tanto fue así que, para evitar las más que posibles negativas al pago, la cláusula séptima del asiento mencionaba esta casuística de manera específica, pues el servicio "es en la forma del que estos Reynos hazen de los Millones, en que todos pagan sin perjuyzio de sus noblezas" 17 .

Aclaradas estas cuestiones, lo más importante para los granadinos -en quienes, evidentemente, recayó la mayor carga- fue fijar por escrito los beneficios de que la nación morisca disfrutaría a cambio de su "gracioso donativo". De ello, se ocupó el primer bloque de normas, entre las cuales pueden encontrarse cuatro ideas principales, todas ellas objeto de atención de los neoconversos desde el momento mismo de su establecimiento en Castilla y de la promulgación de la pragmática de $1572^{18}$. La primera de esas ideas es la relativa al tratamiento que, como colectivo, debía recibir la minoría, cuestión aclarada en la cláusula inicial con un lacónico deseo regio de que los "dichos naturales (...) fuessen tenidos por Christianos viejos". Más importancia revistieron las siguientes disposiciones. De ellas, la segunda, tercera y quinta se refirieron al siempre espinoso asunto de la lista, fijando la elaboración de nuevos padrones, que revocaban a los anteriores y que habrían de ser publicados en la cabecera de cada partido o corregimiento ${ }^{19}$; admitiendo la posibilidad de cambio de domicilio ${ }^{20}$; estableciendo un modelo único de pasaporte — válido para cuatro meses y para toda

${ }^{15}$ Fernández Chaves, "Identidad y fiscalidad”, pp. 118 y ss. En torno a este asunto, véase también Bravo Caro, "Un impuesto de desterrados", pp. 64-65. Para aclarar de manera fehaciente las posibles contradicciones que pudieran surgir, la disposición octava ordenó que "no se admita competición ninguna de los comprehendidos en él, como se hizo en alguno de los passados, de que resultaron inconuenientes para cumplir dicho seruicio". AMT, sig. 6420, fol. 38r-v.

${ }_{16}^{16}$ Bravo Caro, "Un impuesto de desterrados", p. 57.

${ }^{17}$ AMT, sig. 6420 , fol. 38 r. En todo caso, y ante posibles contingencias, se estableció un primer filtro en la figura de los comisarios del servicio y de los dieces, a cuyo criterio debían someterse en primera instancia todos aquellos que "han sacado algunas executorias" pretendiendo ser cristianos viejos. Sobre la figura y papel de los comisarios y dieces véase Bravo Caro, "Un impuesto de desterrados", p. 60 y, más abajo, apartado IV.

${ }^{18}$ En torno a esta cuestión véase Moreno Díaz del Campo, Los moriscos de La Mancha, pp. 278 y ss.

${ }^{19}$ Cláusula primera. AMT, sig. 6420 , fol. $37 \mathrm{v}$.

${ }^{20}$ Siempre debido a circunstancias excepciones (tales como viudedad o reagrupamiento familiar) y bajo supervisión de las autoridades. Cláusula segunda. AMT, sig. 6420, fol. $37 \mathrm{v}$. 
Castilla — del cual debían beneficiarse todos aquellos moriscos dedicados al comercio que tuvieran necesidad de salir de sus poblaciones de alistamiento y, finalmente, permitiendo que

"los dichos naturales que tratan de labrança para salir a trabajar en las heredades y güertas de los términos de las ciudades y villas y lugares donde viuen, y dormir en las dichas güertas y heredades, lo puedan hazer sin licencia ni passaporte de las justicias, ni que por esta causa los molesten ni procedan contra ellos"21.

Relacionado con todo ello, los "procuradores comissarios" obtuvieron el compromiso regio de permitir la libre disposición de "las herramientas para el uso de los oficios que profesan [los moriscos]", ${ }^{22}$ cuestión que, hasta ese momento, había supuesto un serio escollo debido al celo con el que se habían comportado las autoridades locales, quienes en muchas ocasiones creyeron ver armas donde solo había hoces para segar, punzones de carpintero, raspadores para trabajar el cuero o cuchillos para cortar hortalizas ${ }^{23}$.

Los moriscos también lograron arrancar del Rey la exención del servicio militar, gracia cuya concesión se había perseguido desde 1591 - cuando los granadinos comenzaron a servir como "gastadores" al servicio del rey-alegando el grave perjuicio que tal prestación suponía tanto para la economía de Castilla (por la merma de oficiales y peones) como para la propia capacidad fiscal de la minoría ${ }^{24}$, que "por ocasiones de sacarse en las de guerra gastadores de los dichos naturales, no podían cumplir el dicho seruicio" 25 .

Para concluir con el articulado del asiento, moriscos y Monarquía establecieron toda una serie de precisiones (contenidas en los apartados décimo a decimoséptimo) en las que, en esencia, y como se ha indicado, se estipularon los mecanismos que ambas partes tenían para hacer efectivos sus derechos y obligaciones, tales como el nombramiento de delegados, las condiciones en que unos y otros debían asumir su trabajo y las instancias gubernativas y judiciales a las que se someterían en caso de duda o conflicto.

${ }^{21}$ Cláusula quinta. AMT, sig. 6420, fol. 38r.

${ }^{22}$ Cláusula sexta. AMT, sig. 6420, fol. 38 r.

${ }^{23}$ Moreno Díaz del Campo, Los moriscos de La Mancha, pp. 311-326.

${ }^{24}$ Vincent, "Los moriscos granadinos", pp. 174-177.

${ }^{25}$ Argumentación de la cláusula cuarta del asiento de 1603. AMT, sig. 6420, fol. $37 \mathrm{v}-38 \mathrm{r}$. 


\section{Queda assentada la obligación que los dichos naturales hicieron de pagar a su Magestad. Modos de pago y cantidades.}

Es poco lo que se conoce acerca de los sistemas arbitrados para decidir con cuánto debía contribuir cada morisco. Se sabe, a partir de los estudios ya citados, que el servicio fue un impuesto de capitación personal; también que fueron las propias comunidades moriscas las encargadas de decidir cómo y cuánto debía pagar cada individuo, incluso quiénes debían contribuir. En este sentido, todo indica que pudo haber individuos exentos, no tanto por su ascendiente social, por su poder económico o por su influencia política sino, más bien, por carecer de recursos. De hecho, y como apunta Bernard Vincent, no cabe duda de que el grueso de las contribuciones ofrecidas por los moriscos descansó sobre las elites de la minoría, entre quienes, sin duda, se contaban los individuos más interesados en mantener un contacto fluido con la Corona ${ }^{26}$.

No obstante, también cabe admitir que las diferentes ponderaciones utilizadas para el reparto de las asignaciones personales no fueran iguales en todas las aljamas, así como que no permanecieran inalterables a lo largo del tiempo ${ }^{27}$. De ello dio cuenta Aranda Doncel para quien parece demostrado que el criterio seguido para el reparto sufrió variaciones a lo largo de las casi dos décadas en que permaneció vigente. Para apoyar su afirmación se sirvió del ejemplo de la ciudad y partido de Córdoba, donde, en el primer servicio (1591), la cantidad con la que cada morisco contribuyó fue fija y se tasó en cuarenta reales por vecino, cifra a la que se aña-

\footnotetext{
${ }^{26}$ Vincent, "Los moriscos granadinos", pp. 173-174. Prueba de la importancia que tuvieron esas elites nos la da el hecho de que cuando algunos de estos mercaderes y hombres de negocios pretendieron quedar exentos del pago del servicio, la Corona advirtió que no debían escatimarte recursos en el seguimiento de los pleitos iniciados contra los insumisos, dado que, de lo contrario, se seguiría "notable daño de nuestra real hazienda porque se yban exsentando los más ricos y haçendados y los pobres no podrían pagar el dicho servicio". AGS. CJH, leg. 407, exp. 18. Carta del rey al comisario y dieces del partido de Baeza. 29.VII.1600. Para el caso sevillano véase Fernández Chaves, "Identidad y fiscalidad", pp. $130-131$.

${ }^{27}$ Incluso a pesar de experimentar modificaciones, los criterios empleados en el Reino de Granada con anterioridad a 1570 estuvieron más claros. Según Galán Sánchez y Peinado Santaella (pp. 20-23), inicialmente imperó el criterio demográfico, si bien éste fue conjugado con el de la propiedad dado que "sólo pagaban el servicio aquellos que fuesen propietarios de algún tipo de inmueble o parcela de tierra". En última instancia, y como apunta García Pedraza, ello llevaría al establecimiento de distintos grupos de pecheros desde el momento mismo en el que dejó de importar solo "la mera vecindad" para calcularse las contribuciones en base a "la calidad de las rentas de cada pechero". Véase García Pedraza, "Los cogedores de los servicios", p. 139.
} 
dió un variable, tasado en el 13\% del valor de todas aquellas haciendas que superaran los 58000 ducados $^{28}$, mientras que al menos desde 1603 - acaso desde antes - esa capitación se hizo atendiendo a la riqueza de cada cual.

De que en el servicio de 1603 (también en el de 1597) las contribuciones con las que participaron los moriscos fueron de tipo individual y se estipularon atendiendo a la riqueza personal y de que las condiciones en que se produjo cada pago pudieron variar de una comarca a otra da noticia el caso concreto de Miguel López y Alonso Gómez. En 1599, los dos moriscos, mercaderes y cuñados para más señas, residían en Baeza y reclamaron del Consejo de Hacienda que no se les hiciera pagar nuevamente la contribución a que estaban obligados por haberla satisfecho previamente en Chinchón, desde donde se habían trasladado a la localidad andaluza con posterioridad a $1597^{29}$. Lejos de la petición en sí misma, interesa destacar que las contribuciones que cada comisario les reclamó fueron diferentes: cien ducados (37500 mrs.) en el caso de Chinchón y novecientos reales (30600 mrs.) en Baeza ${ }^{30}$. Tratándose de los mismos individuos, tal situación confirma que las contribuciones reclamadas variaron de una comarca a otra, posiblemente en función de la cantidad asignada a cada territorio y en base al número y a la riqueza de los propios contribuyentes, lo que, de paso, avalaría la existencia de una suerte de sistema de pago por tramos de riqueza. Debido a ello, y a lo fluctuante que debió resultar la hacienda personal de los miembros de cada comunidad, cabe afirmar también que las cantidades satisfechas pudieron oscilar en el transcurso de un mismo servicio y comarca, dándose así modificaciones derivadas de las distintas tasaciones que anualmente tuvieron que hacer los repartidores encargados de decidir a cuánto debían ascender las distintas pechas individuales ${ }^{31}$.

De cómo evolucionaron esas contribuciones pueden ofrecernos una idea aproximada un par de ejemplos regionales, aquellos que, en relación al tema tratado, consienten un acercamiento más fiable: el distrito de Jaén, donde la diferencia entre lo pagado en 1592 y aquello otro que se entregó

${ }^{28}$ Aranda Doncel, Los moriscos en tierras de Córdoba, pp. 240-253.

${ }^{29}$ AGS. CJH, leg. 390, exp. 6. El asunto coleaba un año después, cuando el procurador de los moriscos solicitó, nuevamente, que a sus representados no se les cobrase dos veces el servicio. AGS. CJH, leg. 405, exp. 12.

${ }^{30}$ AGS. CJH, leg. 390, exp. 6.

${ }^{31}$ Así lo documentó en su día Bravo Caro para Antequera a raíz del pormenorizado estudio de los "desembolsos" que hicieron los granadinos de dicha localidad en 1603 y 1605. Véase Bravo Caro, "Un impuesto de desterrados...", pp. 71-74. 
en 1603 fue de casi 90000 reales, puede servir de ayuda a la hora de comprender dicha situación ${ }^{32}$; como también aquel otro caso representado por las villas alcarreñas y madrileñas, para las cuales poseemos datos que, aunque fragmentarios, consienten una tibia aproximación a las cifras locales:

\section{Cuadro 1}

El pago del servicio en las localidades alcarreñas en 1597 y 1603

\begin{tabular}{|l|c|c|}
\hline \multicolumn{1}{|c|}{ PARTIDO } & \multicolumn{2}{c|}{ CANTIDAD PAGADA } \\
\hline & $\mathbf{1 5 9 7}$ & $\mathbf{1 6 0 3}$ \\
\hline Pastrana & 104902 & 112438 \\
\hline Alcalá de Henares & 36883 & 45099 \\
\hline Guadalajara & 19840 & 19844 \\
\hline Mondéjar & 2620 & 2742 \\
\hline Torrelaguna y Uceda & 8406 & $6848^{(1)}$ \\
\hline
\end{tabular}

(1) Sólo Uceda.

FUENTE: Para 1597, García López, Moriscos en tierras de Uceda y Guadalajara, p. 127; para 1603, AGS. CJH, leg. 434, exp. 160.

En todo caso, y a pesar de resultar algo exiguas, las referencias anteriores permiten constatar que, aunque cambiantes, las cantidades pagadas por los moriscos se mantuvieron muy estables. De hecho, un examen a los datos reflejados en el cuadro 1 deja traslucir que, a partir de 1603, incluso teniendo en cuenta el aumento de las contribuciones en términos absolutos, la presión sobre los miembros de la minoría se rebajó considerablemente, dado que el impuesto se pagó en el doble de tiempo.

${ }^{32}$ Exactamente 88481, de los 104395 de 1592 a los 192876 que se pagaron a inicios del XVII. Informaciones más aisladas aún dan cuenta de cómo, en el primer servicio, los moriscos del distrito de Guadix, Baza y Almería pagaron ocho millones de maravedíes (21333 ducados). AGS. CJH, leg. 374, exp. 9. 
Cuadro 2

El servicio morisco de 1603. Contribuciones por regiones

\begin{tabular}{|l|c|c|}
\hline \multicolumn{1}{|c|}{ REGIÓN } & $\begin{array}{c}\text { CANTIDAD ASIGNADA } \\
\text { (en reales) }\end{array}$ & \% SOBRE EL TOTAL \\
\hline Reino de Granada & 261750 & 8,57 \\
\hline Andalucía & 1195422 & 39,13 \\
\hline Castilla la Nueva & 1028281 & 33,66 \\
\hline Reino de Murcia & 244645 & 8,01 \\
\hline Castilla la Vieja & 161068 & 5,27 \\
\hline Extremadura & 163632 & 100 \\
\hline TOTAL (en reales) & 3054798 & - \\
\hline TOTAL (en ducados) & 276968,35 & \\
\hline
\end{tabular}

FUENTE: AGS. CJH, leg. 434, exp. 16.

Por otra parte, el que, en relación al servicio de 1603, pueda contarse con cantidades detalladas resulta de gran ayuda a la hora de establecer con precisión el esfuerzo de cada región en la contribución final. En este sentido, y para comparar, puede recurrirse a los datos de población morisca relativos a la expulsión, si bien con ciertas reservas ${ }^{33}$. Así las cosas, el cruce de informaciones confirma que Andalucía y Castilla la Nueva fueron las regiones que más contribuyeron. Junto a ellas el antiguo reino nazarí, donde el peso de lo pagado en concepto de servicio fue más de seis puntos superior en relación a su población, algo que permite afirmar que esos tres territorios no sólo reunían a la inmensa mayoría de los moriscos que contribuyeron al servicio, sino que, además, y dado que nos situamos ante un impuesto que se pagó en función de la riqueza personal, eran las regiones donde residían los moriscos con mayor capacidad adquisitiva.

${ }^{33}$ En relación con ello pueden plantearse varios inconvenientes. En primer lugar, que, como apuntó Lapeyre (pp. 205-206), son unas cifras de mínimos, que incluso presentan problemas, sobre todo para el Reino de Granada, para Andalucía y las comarcas murcianas. También debe tenerse presente que esos mismos datos demográficos son posteriores a la fecha del servicio, lo cual no deja de ser una distorsión que, en todo caso, parece difícil de salvar, dado que no se poseen referencias de conjunto para los primeros años del Seiscientos. Finalmente, hay que advertir que las propias cifras de Lapeyre incluyen no solo a los granadinos sino también a los "moriscos antiguos" (mudéjares), poco representativos a nivel global, pero exentos del donativo. A pesar de ello, y a título meramente orientativo, las cifras del historiador francés consienten una aproximación inicial. 


\section{Cuadro 3}

El servicio morisco de 1603. Comparación cantidad asignada-demografía

\begin{tabular}{|l|c|c|c|c|}
\hline \multirow{2}{*}{ REGIÓN } & \multicolumn{2}{|c|}{ SERVICIO } & \multicolumn{2}{c|}{ POB. MORISCA EN 1609 } \\
\cline { 2 - 5 } & $\begin{array}{c}\text { CANTIDAD } \\
\text { ASIGNADA } \\
\text { (reales) }\end{array}$ & $\%$ & POBLACIÓN & $\%$ \\
\hline Reino de Granada & 261750 & 8,57 & 2026 & 2,26 \\
\hline Andalucía & 1195422 & 39,13 & 29939 & 33,46 \\
\hline Castilla la Nueva & 1028281 & 33,66 & 27654 & 30,91 \\
\hline Reino de Murcia* & 244645 & 8,01 & 13552 & 15,15 \\
\hline Castilla la Vieja & 161068 & 5,27 & 8317 & 9,30 \\
\hline Extremadura & 163632 & 5,36 & 7978 & 8,92 \\
\hline
\end{tabular}

\section{Gráfico 1}

El servicio morisco de 1603. Comparación cantidad asignada-demografía (porcentajes)

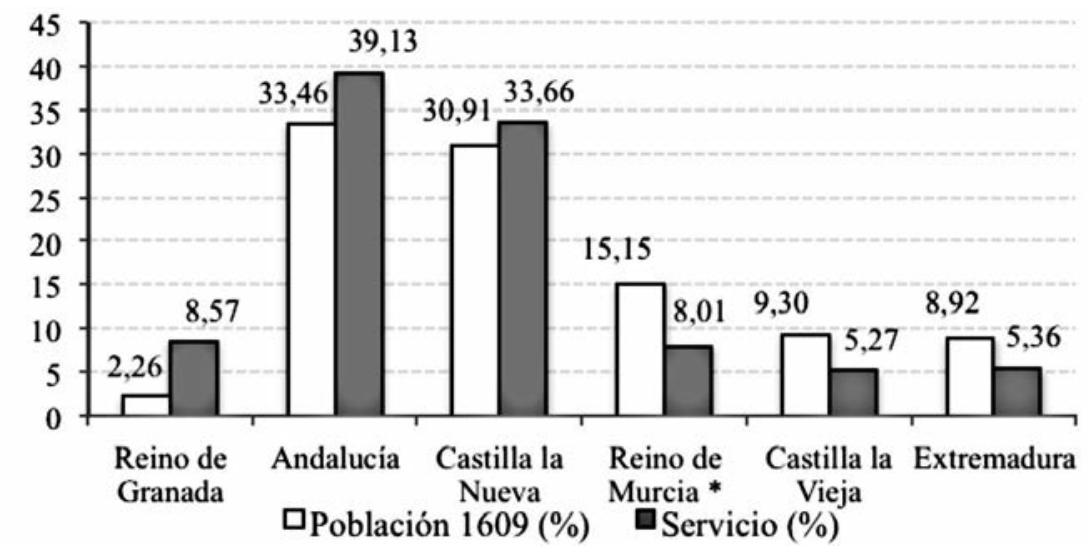

* Incluye localidades de Albacete.

FUENTE (cuadro 3 y gráfico 1): Para el servicio AGS. CJH, leg 434, exp. 16. Para población Lapeyre, Géographie de l'Espagne morisque, pp. 198-200 (ambas Castillas y Extremadura) y 205 (resto de territorios) 
Aparte de lo dicho hasta ahora, la documentación relativa a la negociación y pago del servicio de 1603 proporciona otros datos no menos importantes. Más arriba ha quedado dicho que los moriscos contribuyeron en 1591 y 1597 con 200000 ducados a razón de 50000 anuales y que, como indicó en su día el profesor Vincent, la aportación al servicio de 1603 se vio reducida en un $25 \%$ anual dado que los 240000 ducados entonces acordados se repartían no en cuatro sino en ocho anualidades ${ }^{34}$. Sin embargo, la cantidad con la que los granadinos contribuyeron al servicio de 1603 fue algo superior porque los moriscos tuvieron que añadir otros 10000 ducados entregados al duque de Lerma en concepto de "donativo" 35 y afrontar el pago de los salarios de los comisarios que se encargaron de recaudar el propio servicio.

\section{Cuadro 4}

El servicio morisco de 1603. Contribuciones por partidos (en reales)

\begin{tabular}{|c|c|c|c|c|c|}
\hline Demarcación & $\begin{array}{l}\text { Pago } \\
\text { primer } \\
\text { plazo }^{(1)}\end{array}$ & $\begin{array}{c}\text { Donativo } \\
\text { a Lerma }\end{array}$ & $\begin{array}{c}\text { Pago anual } \\
\text { resto de } \\
\text { plazos }\end{array}$ & $\begin{array}{c}\text { Total } \\
\text { compro- } \\
\text { metido }\end{array}$ & $\begin{array}{l}\text { Comisario } \\
\text { recaudador }\end{array}$ \\
\hline \multicolumn{6}{|l|}{ Reino de Granada } \\
\hline Granada y su partido & 32455 & 6483 & 19513 & 169046 & \multirow{3}{*}{ Juan de León Aduladín } \\
\hline Guadix y su partido & 6746 & 1246 & 3878 & 33892 & \\
\hline Málaga y su partido & 2213 & 200 & 1548 & 13049 & \\
\hline Antequera y su partido & 6303 & 1093 & 3720 & 32343 & \multirow{2}{*}{ Jerónimo Serrano } \\
\hline Ronda y su partido & 2500 & 470 & 1560 & 13420 & \\
\hline SUBTOTAL & 50217 & 9492 & 30219 & 261750 & \\
\hline
\end{tabular}

${ }^{34}$ Aunque de manera indirecta, "garantizaba su continuidad a más largo plazo y limitaba las posibilidades de que los moriscos se pudieran concertar entre ellos". Vincent, "Los moriscos granadinos", p. 173. No obstante, queda por confirmar si el pago de la última anualidad se hizo efectivo, dado que la expulsión fue decretada en julio de 1610, pero ya desde meses antes había granadinos camino del exilio en virtud de la autorización regia concedida en diciembre de 1609.

${ }^{35}$ Bravo Caro, "Un impuesto de desterrados", p. 57. 


\begin{tabular}{|c|c|c|c|c|c|}
\hline Demarcación & $\begin{array}{l}\text { Pago } \\
\text { primer } \\
\text { plazo }^{(1)}\end{array}$ & \begin{tabular}{|c|} 
Donativo \\
a Lerma $^{(2)}$
\end{tabular} & \begin{tabular}{|} 
Pago anual \\
resto de \\
plazos
\end{tabular} & $\begin{array}{c}\text { Total } \\
\text { compro- } \\
\text { metido }\end{array}$ & $\begin{array}{l}\text { Comisario } \\
\text { recaudador }\end{array}$ \\
\hline \multicolumn{6}{|l|}{ Andalucía } \\
\hline Córdoba y su partido & 30390 & 5940 & 18794 & 161948 & \multirow{5}{*}{ Jerónimo Serrano } \\
\hline Priego y su partido & 18713 & 3603 & 11623 & 100074 & \\
\hline Écija y su partido & 17577 & 3332 & 10931 & 94094 & \\
\hline Cádiz y su partido & 906 & 206 & 692 & 5750 & \\
\hline Gibraltar y su partido & 416 & 116 & 300 & 2516 & \\
\hline Sevilla y su partido & 55217 & 10922 & 33196 & 287589 & \multirow{2}{*}{$\begin{array}{l}\text { Alonso Hernández } \\
\text { de Represa }\end{array}$} \\
\hline $\begin{array}{l}\text { Jerez de la Frontera y su } \\
\text { partido }\end{array}$ & 4536 & 906 & 3040 & 25816 & \\
\hline $\begin{array}{l}\text { Morón y El Arahal y sus } \\
\text { partidos }\end{array}$ & 2050 & - & 1274 & 10968 & \\
\hline Baeza y su partido & 54833 & - & 33850 & 291783 & Miguel Fernández Cárdenas \\
\hline Jaén y su partido & 36286 & - & 22370 & 192876 & \multirow{2}{*}{ Diego Hernández Navarro } \\
\hline Martos y su partido & 4438 & - & 2510 & 22008 & \\
\hline SUBTOTAL & 225362 & - & 138580 & 1195422 & \\
\hline \multicolumn{6}{|l|}{ Castilla la Nueva } \\
\hline Campo de Montiel & 13340 & - & 8295 & 71405 & Diego Hernández Navarro \\
\hline Ciudad Real y su partido & 13183 & 2538 & 8157 & 70282 & \multirow{7}{*}{ Martín de Toledo } \\
\hline Almodóvar y su partido & 1181 & 206 & 750 & 6431 & \\
\hline Almagro y su partido & 12718 & - & 7867 & 67787 & \\
\hline San Clemente y su partido & 7416 & - & 4467 & 38685 & \\
\hline Uclés y su partido & 1833 & - & 1077 & 9372 & \\
\hline Almadén y su partido & 825 & - & 588 & 4941 & \\
\hline Alcázar y su partido & 2897 & - & 1668 & 14573 & \\
\hline Pastrana y su partido & 21326 & 4163 & 13016 & 112438 & \multirow{8}{*}{ Jerónimo de Ranera } \\
\hline $\begin{array}{l}\text { Alcalá de Henares y su } \\
\text { partido }\end{array}$ & 8475 & 1633 & 5232 & 45099 & \\
\hline Guadalajara y su partido & 3779 & 719 & 2295 & 19844 & \\
\hline Uceda y su partido & 1248 & 248 & 800 & 6848 & \\
\hline Madrid y su partido & 6461 & 1151 & 4058 & 34867 & \\
\hline Mondéjar y su partido & 502 & 92 & 320 & 2742 & \\
\hline Cuenca y su partido & 2404 & 484 & 1605 & 13639 & \\
\hline Huete y su partido & 2672 & - & 1784 & 15160 & \\
\hline Ocaña y su partido & 38890 & - & 23510 & 203460 & Andrés de Alcalá \\
\hline Toledo y su partido & 48046 & - & 29294 & 253104 & \multirow{2}{*}{ Diego Salcedo } \\
\hline Ávila y su partido & 4916 & - & 2914 & 25314 & \\
\hline Alcaraz y su partido & 2140 & 420 & 1450 & 12290 & Alonso Hernández Luján \\
\hline SUBTOTAL & 194252 & - & 119147 & 1028281 & \\
\hline
\end{tabular}




\begin{tabular}{|c|c|c|c|c|c|}
\hline Demarcación & $\begin{array}{l}\text { Pago } \\
\text { primer } \\
\text { plazo }^{(1)}\end{array}$ & $\begin{array}{c}\text { Donativo } \\
\text { a Lerma }\end{array}$ & $\begin{array}{c}\text { Pago anual } \\
\text { resto de } \\
\text { plazos }\end{array}$ & $\begin{array}{c}\text { Total } \\
\text { compro- } \\
\text { metido }\end{array}$ & $\begin{array}{l}\text { Comisario } \\
\text { recaudador }\end{array}$ \\
\hline \multicolumn{6}{|l|}{ Reino de Murcia } \\
\hline Murcia y su partido & 35795 & - & 22126 & 190677 & \multirow{3}{*}{ Alonso Hernández Luján } \\
\hline Chinchilla y su partido & 5599 & - & 3473 & 29910 & \\
\hline Caravaca y su partido & 4269 & - & 2827 & 24058 & \\
\hline SUBTOTAL & 45663 & & 28426 & 244645 & \\
\hline \multicolumn{6}{|l|}{ Castilla la Vieja } \\
\hline Nájera y su partido & 970 & - & 693 & 5821 & \multirow{4}{*}{ Gabriel Fernández } \\
\hline Valladolid y su partido & 8381 & 1440 & 4686 & 41183 & \\
\hline Palencia y su partido & 3105 & 556 & 1785 & 15600 & \\
\hline Melgar y su partido & 1452 & 252 & 744 & 6660 & \\
\hline Segovia y su partido & 4275 & - & 2503 & 21796 & \multirow{6}{*}{ Álvaro Mendoza } \\
\hline Arévalo y su partido & 2237 & - & 1394 & 11995 & \\
\hline Salamanca y su partido & 7055 & - & 4135 & 36000 & \\
\hline Ciudad Rodrigo y su partido & 430 & 80 & 270 & 2320 & \\
\hline $\begin{array}{l}\text { Toro y Zamora y sus } \\
\text { partidos }\end{array}$ & 763 & 148 & 490 & 4193 & \\
\hline $\begin{array}{l}\text { Medina del Campo y su } \\
\text { partido }\end{array}$ & 3236 & 522 & 1752 & 15500 & \\
\hline SUBTOTAL & 31904 & & 18452 & 161068 & \\
\hline \multicolumn{6}{|l|}{ Extremadura } \\
\hline Plasencia y su partido & 4910 & - & 2970 & 25700 & Álvaro Mendoza \\
\hline Zafra y su partido & 7718 & 1500 & 4758 & 41024 & \multirow{10}{*}{ Alonso Hernández Zamit } \\
\hline Badajoz y su partido & 1760 & 330 & 1100 & 9460 & \\
\hline Trujillo y su partido & 2930 & - & 1818 & 15656 & \\
\hline $\begin{array}{l}\text { Villanueva de la Serena } \\
\text { y su partido }\end{array}$ & 3260 & - & 2027 & 17449 & \\
\hline Mérida y su partido & 2264 & - & 1400 & 12064 & \\
\hline Cáceres y su partido & 1327 & - & 761 & 6654 & \\
\hline Alcántara y su partido & 820 & - & 538 & 4586 & \\
\hline $\begin{array}{l}\text { Valencia de Alcántara } \\
\text { y su partido }\end{array}$ & 1620 & - & 950 & 8270 & \\
\hline Llerena y su partido & 4240 & - & 2647 & 22769 & \\
\hline SUBTOTAL & 30849 & & 18969 & 163632 & \\
\hline
\end{tabular}

(1) Incluye donativo a Lerma, salarios del primer plazo y costas procesales.

(2) El estado de conservación del documento impide reflejar la totalidad de las cantidades destinadas al valido, dado que muchas resultan ilegibles. Por los datos disponibles, solo puede saberse que lo pagado se situó en torno al 5\% de lo satisfecho en el primer plazo.

FUENTE: AGS. CJH, leg. 434, exp. 16. Vaya desde aquí nuestro agradecimiento al personal del Archivo General de Simancas por facilitarnos la consulta de dicha documentación. 
De hecho, si todos esos conceptos se suman, la cantidad finalmente comprometida superó en casi treinta y siete mil ducados a la cifra concertada en noviembre de 1602. Así las cosas, en 1603, los moriscos afrontaron no sólo el pago de los 30000 ducados correspondientes al primer plazo. Tal y como se indica al margen en el documento en el que se consignan las cantidades asumidas por cada aljama, también se incluyó en esta primera paga

"lo que se le rrepartió de los X mil ducados del señor duque de Lerma que entran en la primera paga de 603, lo qual sacado de lo que a cada partido [se] le ha rrepartido para la primera paga, todo lo demás es el servicio de su magestad, salarios de los comisarios y otras cosas anejas a él" ${ }^{\prime 36}$.

Por su parte, las cantidades relativas al segundo y sucesivos plazos incluyeron los 30000 ducados anuales correspondientes al servicio en sí mismo a los que se añadieron otros poco más de 2000 destinados a pagar los sueldos de los comisarios ${ }^{37}$, lo cual permite, a efectos de cálculo, conocer el alcance real de la contribución neta correspondiente al servicio y satisfecha por cada comisario ${ }^{38}$.

${ }^{36}$ AGS. CJH, leg. 434, exp. 16. En el concepto "salarios" se incluyen tanto las percepciones que cada comisario debía recibir anualmente como aquellas otras consideradas "de ayuda a estancia en Corte". Finalmente, deben sumarse algo más de dos mil quinientos ducados destinados a sufragar "otras cosas anejas a él [al servicio]", probablemente relacionadas con el dinero que se necesitaba para costear los procesos judiciales surgidos al socaire de la gestión del propio servicio. En última instancia todo ello provocó que la cantidad satisfecha en este primer plazo supusiera en todas las demarcaciones entre un $17 \%$ y un $20 \%$ de lo finalmente pagado.

${ }^{37}$ La situación no era nueva puesto que, en los servicios otorgados a principios del Quinientos en el reino de Granada, los moriscos se comprometieron a contribuir con una cantidad adicional a la estipulada inicialmente con el objetivo de "cubrir los gastos de la operación recaudatoria". En concreto, esos gastos ascendieron a 1200 ducados en 1503 y 1504 y a "una cantidad algo superior a 1000 ducados" en 1511. Véase Galán Sánchez, “«Herejes consentidos»: la justificación...”, p. 176, nota 10.

${ }^{38}$ Véase cuadro 5. 
Gráfico 2

EI servicio morisco de 1603. Conceptos de pago

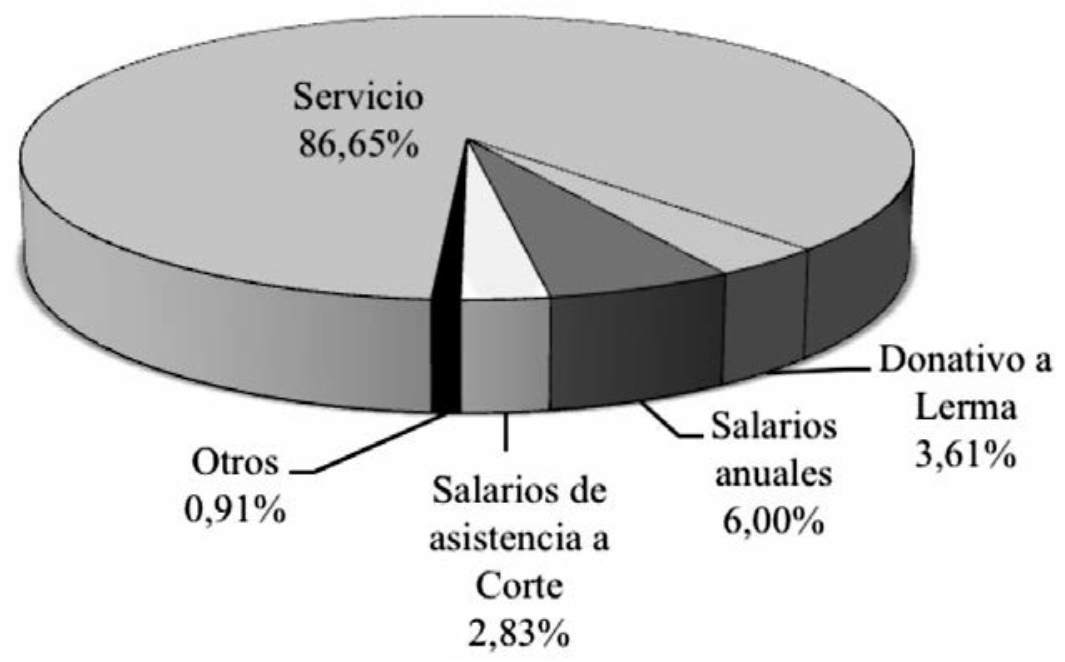

FUENTE: AGS. CJH, leg. 434, exp. 16.

III. Que el repartimiento deste dicho servicio se aya de hazer (...) como se hizo en los seruicios passados. Cuestiones organizativas.

La ordenación y configuración administrativa del servicio es conocida gracias a la disección que de ella hiciera en su día el profesor Bravo Caro. Con dicha base como punto de partida, interesa incidir ahora en aquellas cuestiones relativas a cómo se organizaron las aljamas que decidieron contribuir y en cuáles fueron los mecanismos de alianza o de enfrentamiento que desplegaron los moriscos en función de las más que evidentes rivalidades que se dieron en cada una de las comunidades implicadas en este asunto. No en vano, una lectura atenta del articulado del asiento de 1603 permite constatar que el procedimiento trató de ser mejorado en base, precisamente, a estos choques y problemas. De ahí la importancia de conocerlos. 


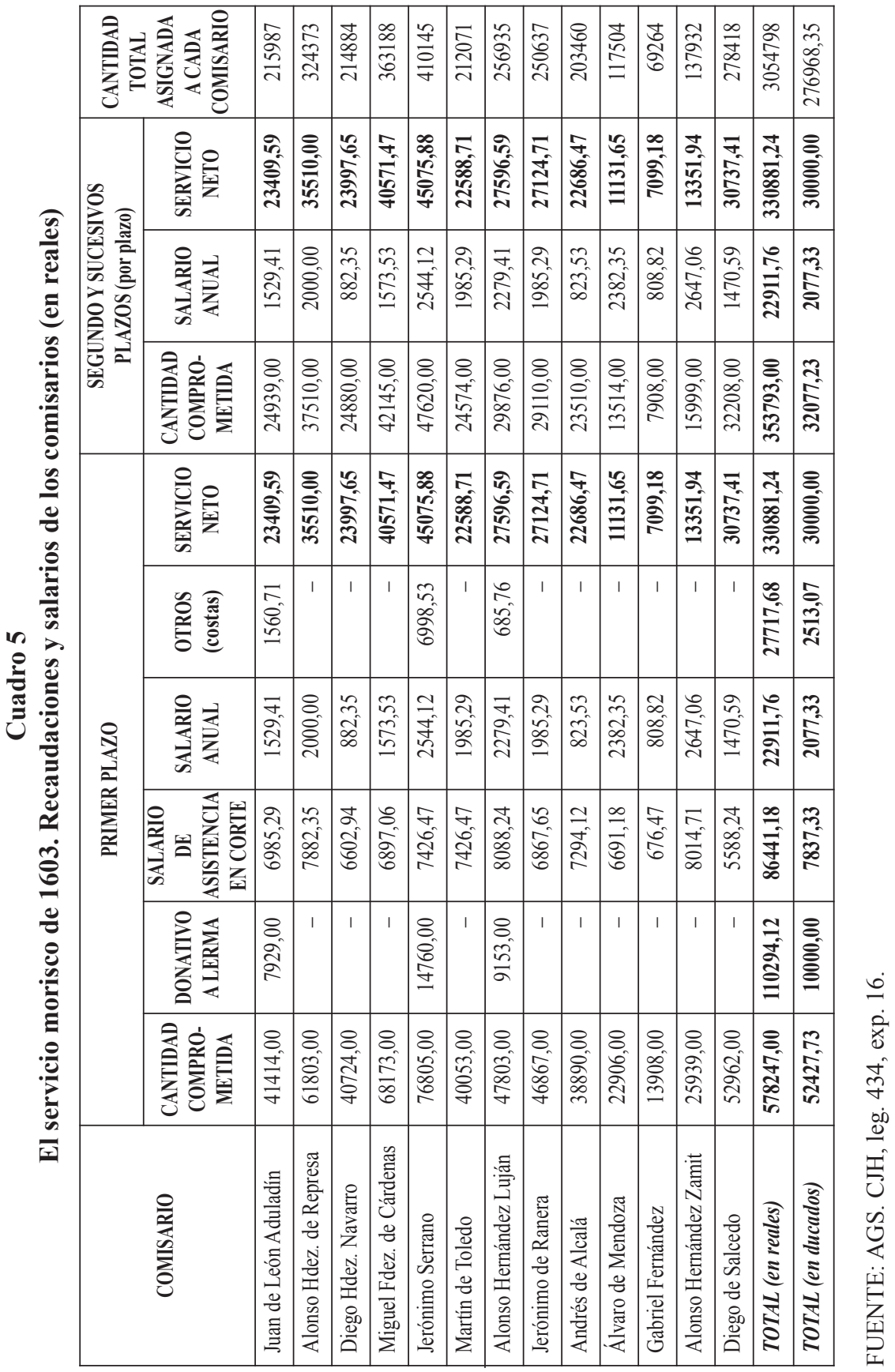

Al-Qantara XXXVIII 1, 2017, pp. 7-43 ISSN 0211-3589 doi: 10.3989/alqantara.2017.001 
Uno de los temas en los que cabría incidir es el relativo a los comisarios encargados de recaudar y gestionar el servicio. Se sabe que sus sueldos fueron fijados a través del "contrato" que cada uno de ellos firmó en la Corte en los meses de noviembre y diciembre de 1602, cuando

"se acordó se pagase a los procurados comissarios el salario de asistencia en Corte [...] a rraçón de quinientos mrvs. cada día y anssimismo se les señaló el salario que habían de haber en cada un año por beneficiar sus partidos"39.

El cuadro 5 recoge las retribuciones que debían percibir (no se sabe con seguridad si se cobraron) en concepto de salario los comisarios encargados de gestionar el cobro del servicio en cada una de las demarcaciones en que quedó dividido el territorio castellano, así como las cuantías finales asignadas a cada uno de ellos para su recaudación. También deja ver que esas cantidades estuvieron sujetas a variaciones ciertamente significativas, cuya razón de ser se localiza en tres factores muy concretos: la extensión de cada distrito, la población morisca a la que tuvo que atenderse y la riqueza de ésta. Como es de suponer, la geografía morisca jugó un importante papel a la hora de establecer las diferentes áreas de actuación en que los comisarios desempeñaron su trabajo. En relación con este aspecto, se dispone de información suficiente para comparar la situación observada en el cuatrieño 1597-1600 con la del periodo 1603-1610. El cruce de los datos correspondientes a ambos servicios confirma que la estructura no tuvo una organización fija y que la Corona trabajó para construir un organigrama sensato, racional y permanentemente adaptable a aquellas condiciones que facilitaran una labor lo más eficaz posible por parte de los comisarios. De hecho, los dieciocho distritos establecidos en $1597^{40}$ quedaron reducidos a tan sólo trece a partir de 1603 lo cual no quiere decir que únicamente se optara por eliminar demarcacions ${ }^{41}$. De hecho se observa

${ }^{39}$ AGS. CJH, leg. 434, exp. 16. El derecho de cada uno a recibir sus emolumentos está recogido en la cláusula undécima del asiento. AMT, sig. 6420, fol. 38v.

${ }^{40}$ Vincent, "Los moriscos granadinos", p. 173.

${ }^{41}$ Aunque el asiento habla de trece partidos (cláusula decimoquinta. AMT, sig. 6420, fol. 39r.) la situación fue confusa porque, inicialmente, se fijaron doce y la reorganización explicada más abajo volvió a la cifra inicial. Por su parte, Bravo Caro ("Un impuesto de desterrados", p. 58), tomando como referencia las instrucciones a comisarios formalizadas en marzo y abril de 1603, vuelve a mencionar doce. Quizás debieron darse más cambios que, por ahora, son desconocidos. 
cómo hubo circunscripciones que permanecieron igual ${ }^{42}$; otras que se subdividieron ${ }^{43} \mathrm{y}$ otras que, al contrario, se fusionaron en un intento de ahorrar costes y esfuerzos ${ }^{44}$.

Es más, al contrario de lo que podría suponerse, la estructura constituida a inicios de cada periodo de cobro tampoco fue fija. Un buen ejemplo de ello se dio a partir de 1598, cuando el Consejo redistribuyó la asignación territorial establecida tan sólo un año antes y suprimió la jurisdicción directa sobre los partidos del Campo de Montiel y de Málaga, que

“... fueron y los benefiçiaron otros comissarios en la primera paga de este serviçio y para las tres que restan se quitó a los que tenían y se anexaron [para] que los beneficiase el comissario del partido de Baeza" ${ }^{45}$.

De hecho, el cambio a que dio lugar esa reorganización seguía manteniéndose cinco años después cuando, ante la puesta en marcha del nuevo entramado recaudador, el Consejo asignó a cada comisario los partidos y corregimientos en los que debía llevar a cabo su labor. Similar situación, pero a la inversa, se dio en 1603, momento en el que los territorios agrupados bajo la autoridad de los comisarios Álvaro de Mendoza y Andrés de Alcalá fueron reorganizados debido a la más que probable queja de los moriscos radicados en la Corte, quienes por auto del Consejo de 25 de enero lograron "que se de al comisario de Valladolid la comyssion de su partido y de los demás que tuvo en el seruiçio passado" 46 .

${ }^{42}$ Como fue el caso de los corregimientos de Toledo y Ávila (gestionados juntos) o de Sevilla y los reinos de Granada y Murcia

${ }^{43}$ Así ocurre en el ejemplo ya visto de Baeza y Córdoba, que comenzaron 1597 unidas y que en 1603 eran tres demarcaciones diferentes.

${ }^{44}$ Los más significativos son los referentes a Castilla la Nueva, La Mancha y Castilla la Vieja.

${ }^{45}$ AGS. CJH, leg. 374, exp. 9. 21.X.1598. Notificación de Juan de los Ríos, contador del servicio.

${ }^{46}$ AGS. CJH, leg. 434, exp. 16. 25.01.1603. La nueva distribución territorial fue aprobada el 20 de marzo y privó a Andrés de Alcalá (comisario de Ocaña) de la recaudación en Segovia, Arévalo, Fuentidueña y Nájera. Estos partidos fueron redistribuidos entre Álvaro de Mendoza (a cuyo cargo quedaron Segovia y Arévalo además de Salamanca, Plasencia, Ciudad Rodrigo, Toro y Zamora y Medina del Campo) y Gabriel Fernández, el recaudador vallisoletano, a quien, además, le fue entregada la gestión de Palencia, Melgar de Fernamental y Fuentidueña y Nájera. 


\section{Cuadro 6}

\section{Comisarios encargados del cobro del servicio morisco y demarcaciones bajo su jurisdicción}

\begin{tabular}{|c|c|c|}
\hline \multirow{2}{*}{ DEMARCACIÓN ${ }^{(1)}$} & \multicolumn{2}{|c|}{ PERIODO DE COBRO (servicio) } \\
\hline & $1597-1600$ & $1603-1610$ \\
\hline $\begin{array}{l}\text { Sevilla } \\
\text { Sevilla, Jerez de la Frontera, Morón de la Frontera, } \\
\text { El Arahal }\end{array}$ & Alonso Hernández de Represa & Alonso Hernández de Represa \\
\hline $\begin{array}{l}\text { Córdoba } \\
\text { Córdoba, Priego, Antequera, Écija, Ronda, Cádiz, } \\
\text { Gribraltar }\end{array}$ & \multirow{3}{*}{ Diego Hernández Navarro } & Jerónimo de Serrano \\
\hline $\begin{array}{l}\text { Jaén }{ }^{(2)} \\
\text { Jaén, Martos }\end{array}$ & & Diego Hernández Navarro \\
\hline $\begin{array}{l}\text { Baeza }^{(3)} \\
\text { Baeza }\end{array}$ & & \multirow{2}{*}{ Miguel Fernández de Cárdenas } \\
\hline $\begin{array}{l}\text { Campo de Montiel } \\
\text { Villanueva de los Infantes }\end{array}$ & Diego de Vera & \\
\hline $\begin{array}{l}\text { Pastrana } \\
\text { Pastrana, Alcalá de Henares, Guadalajara, Uceda, Ma- } \\
\text { drid, Mondéjar, Cuenca, Huete }\end{array}$ & Jerónimo de Ranera & \multirow[t]{2}{*}{ Jerónimo de Ranera } \\
\hline Cuenca & Íñigo Alarcón & \\
\hline Ocaña & Francisco Hernández Ortega & Andrés de Alcalá \\
\hline $\begin{array}{l}\text { Toledo } \\
\text { Toledo, Ávila }\end{array}$ & Diego de Cárdenas & Diego de Salcedo \\
\hline Almagro & Miguel Sánchez de Viedma & \multirow[b]{2}{*}{ Martín de Toledo } \\
\hline $\begin{array}{l}\text { Ciudad Real } \\
\text { Ciudad Real, Almodóvar del Campo, Almagro, San } \\
\text { Clemente, Uclés, Almadén, Alcázar de Consuegra }\end{array}$ & Martín de Toledo & \\
\hline $\begin{array}{l}\text { Granada } \\
\text { Granada, Guadix, Málaga }\end{array}$ & Juan de León Aduladín & Juan de León Aduladín \\
\hline $\begin{array}{l}\text { Salamanca } \\
\text { Salamanca, Plasencia, Ciudad Rodrigo, Toro y } \\
\text { Zamora, Medina del Campo, Segovia y Arévalo }\end{array}$ & Álvaro de Mendoza & \multirow[t]{2}{*}{ Álvaro de Mendoza } \\
\hline Segovia $^{(4)}$ & Bartolomé Hernández, el Tarife & \\
\hline $\begin{array}{l}\text { Valladolid } \\
\text { Valladolid, Palencia, Arévalo, Melgar de Fernamental, } \\
\text { Fuentidueña y Nájera }\end{array}$ & Vicente Calderón & Gabriel Fernández \\
\hline Jerez de los Caballeros ${ }^{(5)}$ & Alonso Hernández Zamit & \multirow{2}{*}{ Alonso Hernández Zamit } \\
\hline Badajoz & Diego Sánchez & \\
\hline $\begin{array}{l}\text { Murcia } \\
\text { Murcia, Chinchilla, Caravaca, Alcaraz }\end{array}$ & Alonso Hernández & Alonso Hernández Luján \\
\hline
\end{tabular}

(1) Siempre que aparecen, se indican partidos que cada demarcación comprende en 1603. No necesariamente coinciden con los fijados en 1597.

(2) Aunque independiente del partido de Córdoba, en el servicio de 1597 era gestionado por el mismo comisario.

(3) De nueva creación. Se desgaja de Córdoba. Se gestiona junto al Campo de Montiel.

(4) Incorporada al comisario de Salamanca. Pierde autonomía de 1597.

${ }^{(5)}$ La villa de referencia (cabecera) en 1603 es Zafra.

FUENTE: Para 1597, AGS. CMC. $3^{\text {a }}$ época. Leg. 3.546., exp. 21 y Vincent (2008), p. 173; para 1603 AGS. CJH, leg. 434, exp. 16. 


\section{Mapa 1}

El servicio morisco de 1603. Distribución territorial de los comisarios encargados del cobro (febrero de 1603)

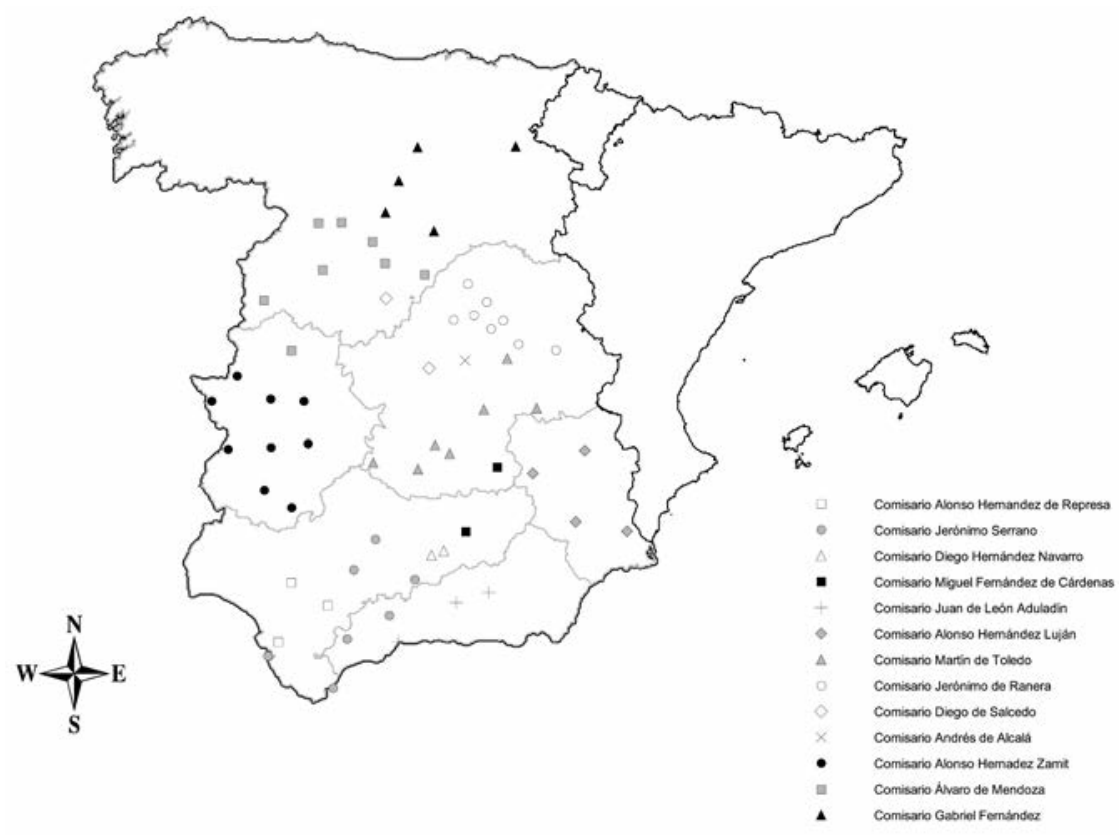

FUENTE: AGS. CJH, leg. 434, exp. 16.

Donde la documentación resulta menos prolija es a la hora de informar acerca de las comunidades que pecharon en cada ocasión. De hecho, para el servicio de 1603-1610 únicamente se poseen los nombres de las cabeceras de partido o de corregimiento, pero ni mucho menos los de las aljamas que debían contribuir. Tanto es así que poco se sabría acerca de las localidades que contribuyeron si no fuera gracias a noticias aisladas que informan acerca del trabajo que tuvieron que desarrollar comisarios muy concretos y, por desgracia, esas informaciones son anteriores al donativo de 1603, aunque nada hace pensar que la geografía de nivel local pudiera variar mucho de un servicio a otro. 


\section{Mapa 2 \\ El servicio morisco de 1597-1600. \\ Aljamas pagadoras en los campos de Calatrava y de Montiel y en los partidos de Ocaña y Baeza}

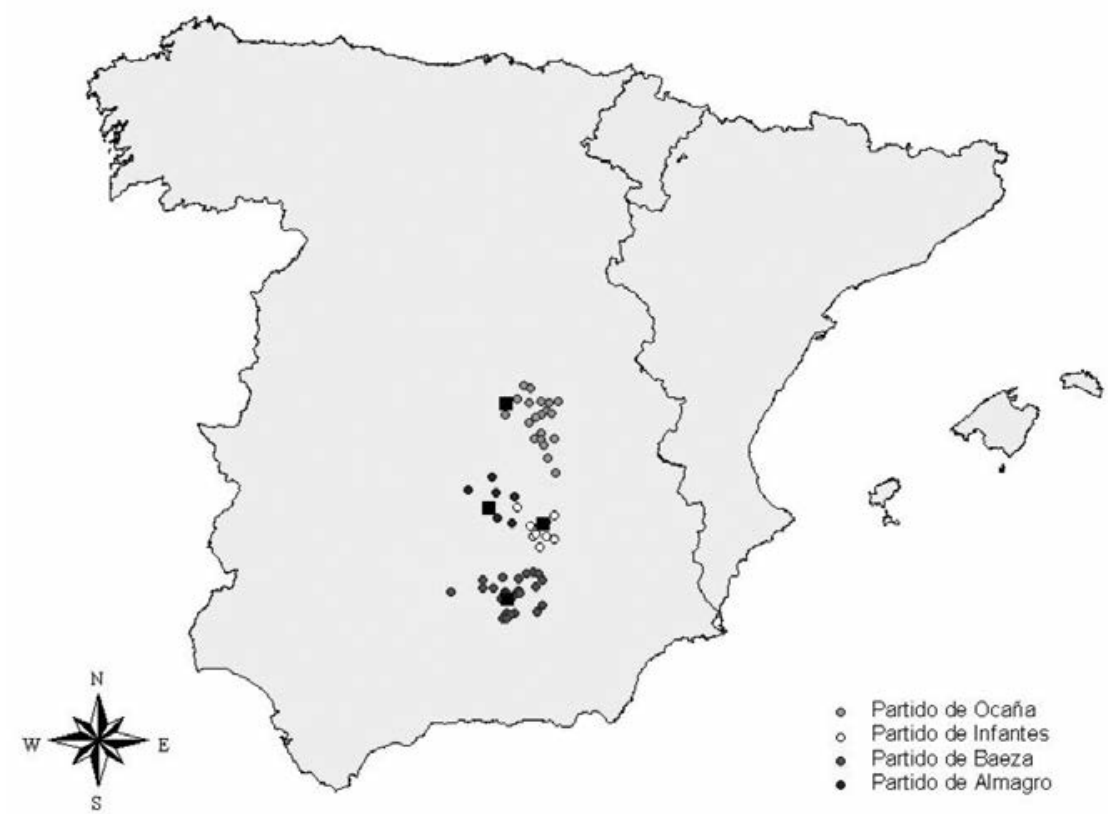

* En cuadro color negro cabecera de cada partido.

Partido de Baeza: Baeza, Úbeda, Bejijar, Ybros, Canena, El Mármol (Marmolejo), Bailén, Baños (de la Encina), Linares, Vilches, Las Navas (de San Juan), Santiesteban del Puerto, Castellar, Sorigüela (del Guadalilmar), Yznatorafe (Iznatoraf), Villanueva del Arzobispo, Villacarrillo, Cazorla, Quesada, El Hiruela (La Iruela), Xodar, Bedmar, Garciez, Ximena, Albanchez, Torres, La Torreperogil y Saviote.

Campo de Calatrava: Ciudad Real, Almagro, Daimiel, Villarrubia de los Ojos, Manzanares, Valdepeñas y Moral de Calatrava.

Partido de Ocaña: Vilarrejo de Salvanés, Fuentidueña de Tajo, Santa Cruz de la Zarza, Villarrubia de Santiago, Tarancón, Rozalén del Monte, Tribaldos, Torrubia, Almendros, Horcajo de Santiago, Dos Barrios, Cabezamesada, Corral de Almaguer, Villanueva de Alcardete, Puebla de Almoradiel, Hinojosos, Quintanar de la Orden, El Toboso, Pedro Muñoz, Socuéllamos.

Campo de Montiel: Membrilla, Villahermosa, Montiel, Fuenllana, Villanueva de los Infantes, Torre de Juan Abad, Cózar, Almedina, Terrinches, Villamanrique.

FUENTE: Para los campos de Calatrava y Montiel y para el partido de Ocaña, AGS. CMC.

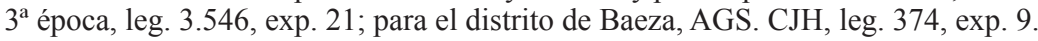


En todo caso, lo observado hasta aquí permite constatar que el sistema, aunque construido, organizado y controlado por el Consejo de Hacienda, hizo gala de una notable descentralización. Evidentemente, a la cabeza de todo él se encontraba el propio Consejo, donde, en relación al servicio morisco, tuvieron competencias varios personajes. Como es obvio, y en primer lugar, el propio Presidente, al que se encuentra de manera frecuente intercambiando correspondencia tanto con el Rey y con Lerma como con los propios comisarios. Junto al marqués de Poza, también cabe destacar la labor desarrollada por el "contador del servicio", cargo que, al menos desde 1602, recaía en Juan Ríos Campuzano, escribano del Consejo ${ }^{47}$. Finalmente, puede hablarse de dos personajes más, siempre presentes en la Corte: en primer lugar, el "Protector de los moriscos", una suerte de apoderado de la nación morisca encargado de mediar entre ésta y la Corona y no sólo en lo relativo al asunto del servicio ${ }^{48}$. Junto a él, el "Procurador General del servicio", que en 1603 se liga a la persona de Jerónimo Ranera, quien, a su vez, era el comisario encargado de cobrar el impuesto en la Alcarria, norte de Cuenca, pueblos del valle del Henares y localidades madrileñas.

Si la labor ejercida por este procurador era importante, no fue menos significativa la que desempeñaron los delegados territoriales, encargados, al principio, de representar a las aljamas de cada región y de negociar con la Corona la concesión y condiciones de cada servicio. Por regla general, una vez constituido el asiento negociado en la Corte, estos mismos personajes actuaron también como comisarios encargados de cobrar el "donativo" y de rendir cuentas ante el Consejo. Huelga decir que cada uno de ellos hubo de contar con el beneplácito previo de los suyos, visualizado a través de la delegación de poderes que, desde el ámbito local a la esfera regional, se fue construyendo en el conjunto de las aljamas castellanas ${ }^{49}$. De todo ello informan Magán y Sánchez cuando describen el procedimiento que siguieron las comunidades de Illescas y Borox para designar al representante local quien, a su vez,

${ }^{47}$ AGS. CJH, leg. 460, exp. 7.

${ }^{48}$ Podemos hablar incluso de un Teniente de Protector, cargo que en 1601 recae en Antonio Navarro de Aróstegui, secretario del rey (AGS. CJH, leg. 410, exp. 15). De las funciones del protector se da cuenta en Sánchez Romeralo, "El Conde de Orgaz, protector de los moriscos".

${ }^{49} \mathrm{El}$ modelo de poder otorgado a dichos procuradores en 1602 para que negociasen el servicio del año siguiente fue publicado en Domínguez Ortiz y Vincent, Historia de los moriscos, p. 280. 
debía participar en el proceso de elección del correspondiente procurador regional ${ }^{50}$. También Bravo Caro, quien da cuenta de cómo, cuando la Corona intentó reunirlos para negociar el asiento de 1603, muchos encontraron serias dificultades para ejercer su cargo, dado que se presentaron en la Corte con los poderes otorgados para servicios pasados y allí coincidieron con aquellos otros nombrados para esa ocasión, motivo por el cual "se travaron pleitos entre los unos y los otros" ${ }^{51}$.

La figura de estos procuradores introduce de lleno en la organización del entramado a una escala menor. Desde este punto de vista, y siguiendo a Vincent, podría hablarse de dos niveles, uno regional/comarcal y otro puramente local ${ }^{52}$. Dentro de la esfera regional, el actor principal fue el propio comisario que, normalmente, formó parte de esa élite heredera de la granadina, cuya influencia descansaba ya sobre una riqueza relativamente importante construida tomando como base el negocio comercial y la explotación de tierras ${ }^{53}$. En ocasiones, puede localizarse un personaje más; se trata, en realidad, de un "comisario interino" - al que la documentación suele denominar como "juez comisario" o "teniente de comisario"- que ejerce su labor en ausencia del titular. Es algo que se dio, por ejemplo, en el caso del ya mencionado Ranera, quien, al pasar largas temporadas en la Corte, se vio obligado a delegar en la persona de un tal Miguel López ${ }^{54}$.

Por tanto, y aunque es cierto que la designación de unos y otros fue competencia exclusiva de la Corona ${ }^{55}$, no es menos verdad que la voz

${ }^{50}$ Magán y Sánchez, Moriscos granadinos en La Sagra de Toledo, p. 70. En el caso de Borox — con documentos fechados el 23.V.1603 y el 10.VIII.1604 - se indica, incluso, que los representantes de la villa deben desplazarse a Pastrana, probablemente porque la persona con la que debían tratar era el propio Ranera, de quien ya se sabe que residía a caballo entre la Corte y la villa de los Éboli.

${ }^{51}$ Bravo Caro, "Un impuesto de desterrados", p. 51. Dadas las dificultades, el Presidente del Consejo volvió a citarlos tiempo después y en el intervalo recomendó a gobernadores y corregidores que favorecieran la elección de "los procuradores antiguos que se avían allado en los demás serviçios por tenerse de su voluntad más satisfaçión". Carta del Presidente de Hacienda al Rey. 26.VI.1601. AGS. CJH, leg. 412, exp. 14.

${ }^{52}$ Vincent, "Los moriscos granadinos", p. 172.

${ }^{53}$ Véanse Fernández Chaves, "Identidad y fiscalidad”, p. 118; Moreno Díaz del Campo, "Aproximación a las fuentes", pp. 10-15 y Pérez García y Fernández Chaves, "Los hermanos Berrio: capital morisco"

${ }^{54}$ AGS. CJH, leg. 460, exp. 7.

${ }^{55}$ Los nombramientos de representantes y comisario de cada partido debían hacerse ante el gobernador o corregidor correspondiente y luego remitirse al Consejo donde se formalizaba el "contrato" por el cual los moriscos se obligaban al pago del servicio. Cláusula decimocuarta. AMT, sig. 6420, fol. 39r. 
de la comunidad local jugó un importante papel. De hecho, la propuesta de candidaturas para ejercer este puesto siempre fue remitida al Consejo por una comisión, normalmente formada por una decena de miembros (de ahí que se les denomine "dieces") ${ }^{56}$, en la que, como se ha indicado, entraba lo más granado de la comunidad morisca de cada partido o comarca ${ }^{57}$.

\section{Gráfico 3}

El servicio morisco de 1603. Cantidades asignadas a los comisarios (en reales)

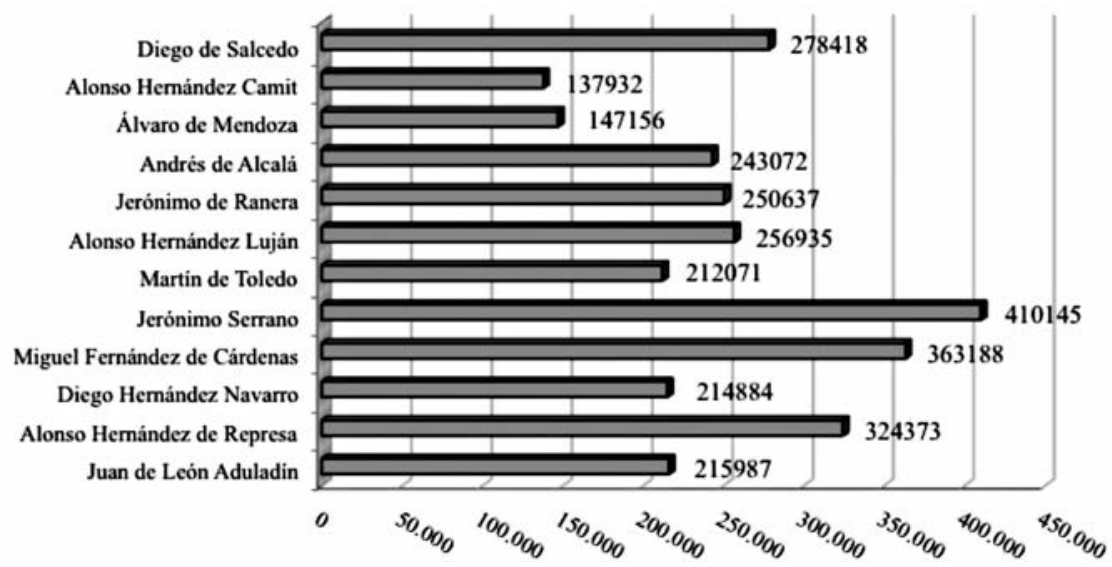

FUENTE: AGS. CJH, leg. 434, exp. 16.

Dieces y procurador (convertido ya en comisario) formaban ese grupo que, según Vincent, tuvo a su cargo la misión de coordinar el cobro del impuesto en cada distrito y de enviar a la Corte a los representantes encargados de supervisar el reparto "al por mayor", que debía dar con la cifra asignada a cada comisario ${ }^{58}$, distribuida luego entre el resto de las comunidades.

${ }^{56}$ AGS. CJH, leg. 443, exp. 5.

${ }^{57}$ Bravo Caro, "Un impuesto de desterrados", p. 59. El sistema, pues, era muy similar al utilizado en el reino de Granada, si bien parece deducirse que, en Castilla, las aljamas dispusieron de un mayor margen de maniobra. Para posibles comparaciones, véase Galán Sánchez, "El dinero del rey y la «ley de la comunidad»" y García Pedraza, "Los cogedores de los servicios".

${ }^{58}$ Vincent, "Los moriscos granadinos", p. 172. 
En el reparto "al por menor", intervenían, evidentemente, los dieces - con una clara labor de supervisión y control en este caso-, pero también los delegados que cada aljama enviaba a la cabecera de partido tal y como se sabe que ocurrió en Quintanar de la Orden, localidad para la que se han localizado los poderes otorgados a Pedro de Guevara y a Juan Martínez de Guevara, quienes, con motivo de las negociaciones del servicio de 1597, tuvieron que desplazarse a Ocaña para asistir

"para el jueves primero que viene, que se contarán diez y nueve del presente mes
[de octubre de 1596] y en rraçón de un mandamiento que del señor Gouernador se
trujo para que para el dicho día estuviésemos en la dicha villa sobre cierto repar-
timiento que se ha de hacer y hace por su Magestad a los naturales del rreino de
Granada y para que se obliguen en lo que de dicho repartimiento de derive"59.

En última instancia, ellos fueron los que desempeñaron el oficio de repartidores (o cogedores), si así se quiere ver, el escalón inferior de todo el sistema, dado que ejercieron "las funciones de tasadores del patrimonio de las distintas familias afectadas por la orden" y se encargaron de "elaborar una nómina especificando la cantidad de reales asignada individualmente conforme a la hacienda que cada uno tuviese" ${ }^{60}$. No es de extrañar, por ello, que tanto la excesiva exposición pública que conllevaba dicho cargo como el mucho trabajo que acarreaba fueran causa suficiente para que algunos decidieran plantear su renuncia tras algún tiempo en el ejercicio del mismo. Así pareció ocurrir con Jerónimo de Mendoza, Pedro de Peñalosa y Miguel Vázquez, tres de los repartidores del último servicio en la ciudad de Toledo, quienes después de varios años al servicio de la Corona manifestaron su intención de retirarse por tener "neçesidad de acudir a sus haçiendas, que las tienen perdidas de causa de la ocupaçión del dicho ofiçio" 61 .

${ }^{59}$ AHP To. Protocolos leg. 13162, s.f. 15.IX.1596. El sistema de reparto fue muy similar al que García Pedraza observa en el reino de Granada, si bien allí se dieron diferencias entre la capital y el resto de localidades. Véase García Pedraza, "Los cogedores de los servicios", pp. 143-145.

${ }^{60}$ Bravo Caro, "Un impuesto de desterrados", p. 60.

${ }^{61}$ AGS. CJH, leg. 478, exp. 6. Según la certificación enviada al Consejo por Diego Díaz de Escobar, escribano de la ciudad, Miguel Vázquez había ejercido dicho oficio durante los años 1605 y 1606; Pedro de Peñalosa entre 1604 y 1606 y Jerónimo de Mendoza desde 1603 hasta 1606. 


\section{Que en lo que toca a este seruicio (...) no se meta (...) sino solo el Consejo de Hacienda. Problemas y conflictos}

Lejos de resultar unánimemente aceptado, el servicio fue cuestionado, provocó rivalidades e, incluso, generó conflictos entre los propios moriscos y entre éstos y la Corona. Parte de estos choques vinieron motivados por la existencia de familias que no dudaron en enfrentarse para colocar en tal o cual puesto al candidato que mejor podía defender sus intereses. Un buen ejemplo de ello se dio en la villa de Huete. En 1598, Hernando de Soria, representante de la comunidad local, se dirigió al Consejo de Hacienda. Según su testimonio, algunos de los moriscos de aquel partido habían soportado una presión ciertamente importante en relación al pago de su contribución, dado que las cantidades que habían satisfecho habían sido muy superiores a las que, al parecer, les correspondían. Sin embargo, la queja de los moriscos conquenses no se dirigía contra el Consejo sino hacia "los repartidores que fueron nombrados para el dicho serviçio", quienes les

\footnotetext{
"repartieron mucha más cantidad de maravedís de lo que les perteneçía a pagar conforme a las valoraçiones de sus haçiendas, respecto de que los comissarios que han ydo sobre el dicho serviçio nombraban a sus amigos por repartidores. Y por esta causa, y por ser ynteresados los nombrados y tener muchos deudos y amigos, les descargaron de lo que les perteneçía y agrauan a los dichos sus partes y [a] él sin guardar la orden de las baloraciones" ${ }^{\prime 2}$.
}

Consciente de que la polémica podía afectar negativametnte a los suyos, Soria propuso que la elección de los repartidores no recayera en manos de los comisarios, ni que dependiera de la voluntad de cada comunidad local, sino que se hiciera por sorteo y eliminando siempre a todos aquellos que, previamente, habían desempeñado dicha labor. Por desgracia, no se conoce en qué acabó tal episodio, aunque a juzgar por lo contenido en el asiento del servicio de 1603, parece que el Consejo decidió obviar este tipo de peticiones, dado que ordenó que "en la cobranza y repartimiento deste serviçio se aya de guardar el orden que en los passados en el nombrar Repartidores diezes" ${ }^{63}$. ¿Acaso se impuso, una vez más, el criterio de la elite morisca? Todo indica que pudo ser así.

${ }^{62}$ AGS. CJH, leg. 375, exp. 11.

${ }^{63}$ Cláusula decimocuarta. AMT, sig. 6420, fol. 39r. 
Junto a las disputas entre los moriscos, también podrían señalarse aquellos otros problemas relacionados con la estructura del entramado recaudador. Como ha podido observarse, la organización del servicio implicó a una nada despreciable cantidad de personas y a prácticamente todas las instancias relacionadas con el ejercicio del poder en cada comarca, desde los representantes de la propia minoría, hasta las autoridades municipales y los delegados de la Corona. Así todo, la designación de un nuevo comisario no siempre fue fácil porque hubo de venir avalada por las distintas aljamas implicadas en el pago del servicio. Las trabas fueron aún más importantes cuando el cargo quedaba vacante en medio del periodo de cobro y tenía que improvisarse el nombramiento de un sustituto. Cuando así ocurrió, la propuesta de candidato se presentó al Consejo a través del correspondiente delegado regio; sin embargo, esa petición no era sino un mero formalismo posterior a la elección por parte de los propios moriscos. Tanto que, si el elegido no generaba el consenso requerido, el proceso de elección podía derivar en enfrentamientos más o menos importantes entre los moriscos. Así ocurrió en Ocaña tras la dimisión del comisario Francisco Hernández Ortega, cuyo caso, expuesto por Bravo Caro ${ }^{64}$, dio lugar a un complejo proceso en el que tras la renuncia de los dos candidatos a sustituirle parece que se dio, finalmente, con un recaudador no sin antes asistir a complicados tejemanejes - con sobornos y coacciones de por medio- en los que los más sobresalientes representates de la élite comercial morisca de la villa jugaron un importante y no menos interesado pape ${ }^{65}$.

En una situación muy parecida se vieron inmersos los moriscos de Baeza cuando en 1598 falleció el representante que apenas un año antes había sido designado por la aljama de la ciudad. Ante tal contingencia, los moriscos se apresuraron a proponer a Domingo Hernández Casillas, cuñado del fallecido ${ }^{66}$. Sin embargo, y de manera paralela, un tal Jerónimo Ximénez, que se presentó como hijo ilegítimo del anterior comisario, también se dirigió al Consejo para manifestar su intención de

${ }^{64}$ Bravo Caro, "Un impuesto de desterrados", pp. 61-63

${ }^{65}$ En dicho grupo se encontraban personajes como Gonzalo de Campos, Damián de Medrano, Jerónimo de Carmona o Luis de Valencia, todos ellos incluidos entre los mayores propietarios moriscos del partido de Ocaña en el momento de la expulsión. Véase Moreno Díaz del Campo, Los moriscos de La Mancha, pp. 495-497.

${ }^{66}$ AGS. CJH, leg. 374, exp. 9. 
"heredar" el cargo que había ejercido su padre. Su propósito era revocar el nombramiento anterior, aduciendo que su rival había ganado el puesto "con cautelas y engaños" y que no gozaba de la confianza de "los más prinçipales de la çiudad". A pesar de estar bien fundamentada, su candidatura fue rápidamente vetada por el resto de comunidad -O al menos por una mayoría lo suficientemente amplia-, amparándose ésta en que Jerónimo no podía desempeñar el cargo por estar avecindado en Priego y no en Baeza y en que, además, no era conveniente que ejerciera la comisión porque al ser hombre pobre se corría el riesgo de que no pudiera responder a lo que se le encargaba ${ }^{67}$.

Ambos casos muestran de manera muy clara las dificultades que Corona, Consejo y delegados regios encontraron para gestionar el servicio. También, las enormes implicaciones socioeconómicas que llevaba aparejado el hecho de aceptar la responsabilidad de ejercer como comisario; las ambiciones de la elite granadina afincada en Castilla, atenta a que el proceso fuera controlado por personas afines $-y$ hasta dóciles, llegado el caso-; y, finalmente, el no menos activo papel de las propias aljamas, siempre vigilantes ante la necesidad de que el dinero que pagaban fuera convenientemente recaudado y empleado.

Aparte de los conflictos que el servició generó entre los moriscos, también es necesario hacer referencia a aquellas cuestiones relacionadas con las resistencias - cuando no negativas - de algunos cristianos nuevos a pagar la parte que les correspondía. Probablemente, uno de los casos más llamativos fue el protagonizado por Hernán López Elferi, morisco de Pastrana, quien, en 1606, hubo de vérselas con la justicia acusado de andar "induciendo testigos" para interferir en la labor del comisario $^{68}$. Su caso es muy similar al de Juan Mejía, confitero alistado en Murcia ${ }^{69} \mathrm{o}$ al de Bernardino de Billaragut, encarcelado debido a su empeño en tratar de evitar que los moriscos de Málaga contribuyeran al donativo ${ }^{70}$; caso éste último que trasciende la mera negativa al pago, pues, para conseguir la exención, el tal Billaragut no dudaba en aconsejar a los suyos que emprendieran procesos para ver reconocida su supuesta condición de cristiano viejo, ser exonerados y, así, evitar el

${ }^{67}$ AGS. CJH, leg. 374, exp. 9.

${ }^{68}$ AGS. CJH, leg. 460, exp. 7. 17.II.1606

${ }^{69}$ AGS. CJH, leg. 479, exp. 13.

${ }^{70}$ Bravo Caro, "Un impuesto de desterrados", p. 66. 
correspondiente desembolso ${ }^{71}$. A pesar de que estas peticiones fueron relativamente frecuentes; o quizás porque la utilización de tal argumento ya entraba en las previsiones de la Corona, las disposiciones recogidas a tal efecto en el asiento de 1603 fueron tajantes ${ }^{72}$. Así se lo hizo saber el Consejo a un tal Jerónimo Rodríguez, que pretendía no ejercer como cogedor en Pastrana (y no pagar el servicio) por tener "carta executoria del dicho Consejo de Justiçia, en que está declarado por xptiano viejo"73.

Junto a este tipo de actuaciones, pueden señalarse también no aquellos casos en los que se dio una negativa al pago, sino, más bien, un problema con el mismo. De hecho, y al estar ante un impuesto directamente relacionado con la riqueza y con la actividad económica de quien lo paga, resulta fácil comprender que en coyunturas negativas o ante la llegada de episodios adversos, los moriscos pudieran tener ciertas dificultades. Un ejemplo de ello se dio en Alcalá de Henares y su partido donde debido a una climatología adversa, los moriscos se vieron obligados a pedir en varias ocasiones una moratoria ${ }^{74}$ pues una

"avenida e tenpestad que ubo en la dicha villa de Alcalá [...] se llevó las casas y haçiendas de los dichos mis partes y quedaron desnudos y pobres y sin haçiendas de cuya causa no pueden pagar y comen de limosna"75.

La solicitud de los moriscos alcalainos no fue, ni mucho menos, aislada sino que constituyó un argumento recurrente en muchas de las misivas que recibió el Consejo a finales del XVI y se encuadra en el contexto de malas cosechas vivido en Castilla en aquellos años ${ }^{76}$. Tales razonamientos sirvieron de base para que el Conde de Orgaz, en su calidad de Protector de los moriscos, solicitara al presidente Poza que la anualidad correspondiente a 1599 fuera aplazada durante, al menos,

\footnotetext{
${ }^{71}$ De hecho, y como apunta el propio Bravo (“Un impuesto de desterrados”, p. 55.), "no sólo importaba escapar de los tentáculos de una fiscalidad diversificada (...) sino, y es lo más importante, quedar al margen de cualquier vinculación con elementos sociales de indudable marginación en el contexto de la España del momento". Véase también Otero Mondéjar, "Que siendo yo cristiano viejo, la justicia procedió contra mi", pp. 123 y ss.

${ }^{72}$ Como se ha indicado, se ocupaban de estas cuestiones las disposiciones séptima y novena del asiento.

${ }^{73}$ AGS. CJH, leg. 466, exp. 16. 24.VII.1606.

${ }^{74}$ AGS. CJH, leg. 389, exp. 7.

${ }^{75}$ AGS. CJH, leg. 377, exp. 9.

${ }^{76}$ Bravo Caro, "Un impuesto de desterrados", p. 51.
} 
seis meses ${ }^{77}$. Tras no pocas dudas y un no menos intenso debate entre Lerma, el Protector y el presidente de Hacienda ${ }^{78}$, el rey accedió a aplazar el pago, pero no los seis meses solicitados sino tan sólo dos ${ }^{79}$. En la toma de la decisión final tuvo mucho que ver el duque, quien a juzgar por las misivas que intercambió con el presidente del Consejo y con el secretario regio, recogió la idea del conde de Orgaz de mostrarse condescendiente con los moriscos ante el inminente inicio de las negociaciones del donativo de $1603^{80}$. A ello, cabe añadir que el problema planteado entonces sirvió, una vez más, para mejorar la gestión de las contribuciones que aún estaban por llegar. No en vano, y quizás debido a la experiencia acumulada y a la propia labor del conde, esta casuística, fue incorporada al texto del asiento de 1603, al menos en parte, pues la disposición duodécima contempló desde entonces (no se sabe si en anteriores asientos también) la posibilidad de retrasar el pago de cualquier plazo hasta "tres meses después que aya passado la peste"

Cabe mencionar, por último, aquellas otras situaciones en las que determinados moriscos, casi siempre a título individual, decidieron bien negociar con la Corona para obtener unas mejores condiciones en el pago, bien pleitear con los comisarios con el objetivo de demorar los pagos a los que se habían obligado. Aparte de lo visto líneas arriba, dos ejemplos pueden servirnos en esta ocasión. En primer lugar aquel que se relaciona con la petición de los moriscos de Toledo y su tierra. Según se desprende de las solicitudes llegadas al Consejo, los granadinos de la Ciudad Imperial habían contribuido en el servicio de 1591 con 10000 reales más de los que les correspondían. Por ello esperaban que, en su contribución de 1597, se les descontara dicha cantidad. Así lo hicieron saber al Consejo. Sin embargo, todo parece indicar que tuvieron poco éxito en su demanda pues, para entonces, la decisión del monarca era la de mantener la contribución establecida y la de no devolver el sobrante cobrado dado que

"si se huuiessen de restituir a las mismas personas de quien se cobraron sería muy dificultoso [y] ha parecido que será lo mejor distribuirlos en obras pías. Y assí, or-

${ }^{77}$ AGS. CJH, leg. 399, exp. 6.

${ }^{78}$ Parte de las misivas entre los tres en AGS. CJH, leg. 410, exp. 15 y leg. 412, exp. 13.

${ }^{79}$ AGS. CJH, leg. 412, exp. 13. 28.I.1601.

${ }^{80}$ Bravo Caro, "Un impuesto de desterrados", p. 52.

${ }^{81}$ Cláusula duodécima. AMT, sig. 6420 , fol. 38v. La peste también había sido aducida en 1600 como otro de los motivos para solicitar moratorias. AGS. CJH, leg. 399, exp. 6. 
denaréis que si estos diez mil reales no se han cobrado de las tales personas, se cobren luego, y que dellos se den los seis mil a la capilla de los Reyes Viejos de la dicha ciudad de Toledo, para las cosas que se han de renovar y hazer para el servicio della y los otros quatro mil restantes, la mitad al monasterio de las beatas de la vida pobres, y la otra se reparta ente los moriscos pobres de la misma ciudad..." $" 82$.

El otro ejemplo al que puede hacerse referencia es el caso - ya esbozado- de Miguel López y Alonso Gómez, quienes, como es conocido, tuvieron que pagar su contribución dos veces (en Chinchón y en Baeza). En su estrategia, buscaron la participación interesada de las autoridades locales y el choque de éstas y de los delegados señoriales con el propio Consejo para retrasar el pago y, llegado el caso, hacerlo efectivo allí donde resultara menos lesivo a sus intereses ${ }^{83}$. Tal y como ocurrió aquí, la mayor parte de estos litigios se resolvió siempre a favor de la Corona dado que la redacción de las instrucciones por las que se rigió la recaudación del impuesto apenas dejó margen a interpretaciones que pudieran derivar en la asunción de más poder por parte de corregidores, gobernadores o representantes de la justicia local ${ }^{84}$. De hecho, el choque competencial fue uno de los grandes quebraderos de cabeza del Consejo de Hacienda en relación a este asunto ${ }^{85}$, ya que agentes municipales y señoriales y élites locales jugaron la baza de controlar un proceso que, bien gestionado (lo cual no equivale a decir legalmente), podía resultar muy beneficioso. Así parece que pudo ocurrir en Murcia, donde el corregidor hostigó de manera continua al repartidor Fernando de Mendoza, lo que motivó que éste solicitara al monarca que le permitiese llevar armas en el ejercicio de su labor ${ }^{86}$. Aunque con matices, su caso fue muy similar al de Jerónimo Serrano, comisario de las aljamas de Córdoba y su partido, quien hubo de en-

${ }^{82}$ AGS. CJH, leg. 360, exp. 26. 31.VII.1597.

${ }^{83}$ AGS. CJH, leg. 405, exp. 12.

${ }^{84}$ Existe copia de las instrucciones en la documentación simanquina. Un ejemplo de las mismas, aplicado al caso de Jerónimo Serrano, comisario del antiguo Reino de Córdoba, ha sido publicado en Bravo Caro, "Un impuesto de desterrados", pp. 75-81. En todo caso, y por si ello no fuera suficiente, la redacción del "contrato" de 1603-1610 también consagró una cláusula específica a este asunto, en concreto la decimoséptima.

${ }^{85}$ Como surgirían posteriormente en el propio Consejo con la venta de los bienes de los expulsados. Véase Moreno Díaz del Campo, Los moriscos de La Mancha, pp. 434 y ss.

${ }^{86}$ Bravo Caro, "Un impuesto de desterrados", p. 54. La cuestión de las armas y de la autorización de su porte por parte de los "caxeros y cobradores" también es recogida en el asiento de 1603, concretamente en la cláusula decimoquinta. AMT, sig. 6420, fol. 39r. 
frentarse a Gregorio Tamariz, corregidor de Marchena, y a Pedro de Alarcón, su antecesor en el cargo, porque ambos andaban inmiscuyéndose en su labor al amparar a algunos moriscos a los que se les habían embargado ciertos bienes por negarse a pagar ${ }^{87}$. Los conflictos de jurisdicción también se dieron con la justicia señorial. Así ocurrió, por ejemplo, en Pastrana, donde Miguel López, el teniente de comisario de Ranera, se enfrentó a la justicia de los Éboli, opuesta a que se ejecutara una pena pecuniaria contra un morisco acusado de alentar al no pago entre el resto de moriscos de la villa ${ }^{88}$.

Tanto el caso de Murcia, como el de Córdoba o el de Pastrana son muestras claras del intento de los agentes territoriales de controlar un proceso en el que ya sabemos que por expreso deseo de la Corona pudieron contar muy poco. He ahí el principal motivo en el que se sustentó la mayor parte de las quejas elevadas por los granadinos a la Corona, casi siempre, y en virtud de los asientos, resueltas a favor de los moriscos, que hicieron valer lo acordado con el monarca frente a los representantes de éste, por mucho que las quejas de éstos últimos estuvieran fundamentadas. De hecho, lo que verdaderamente pesó en estos casos fue el acuerdo entre rey y minoría, en el que los moriscos ganaron el compromiso de que el proceso sería controlado directamente por ellos salvo cuando el conflicto requiriera de la intervención de un tribunal, en cuyo caso, como es conocido, ambas partes decidieron someterse a la jurisdicción del Consejo de Hacienda, pues

"en raçón del dicho serviçio están ynividas todas las justicias del reyno de todas las causas y negocios tocantes y dependientes del y solo pueden conocer dellas el rreal consejo de la hazienda" ${ }^{89}$.

Quizás fue ahí donde residió la verdadera fuerza de la minoría en el asunto del servicio. A principios del siglo XVII, cuando ya se oían voces en torno a la necesidad de una expulsión y cuando en la Corte se discutía acerca de la conveniencia o no de ejecutar dicho plan, la nación morisca se mostró lo suficientemente cohesionada no sólo como para ofrecer a la Corona un servicio que ascendía a más de un cuarto de millón de ducados, sino también para gestionar su cobro casi

${ }^{87}$ AGS. CJH, leg. 419, exp. 20.

${ }^{88}$ AGS. CJH, leg. 460, exp. 7.

${ }^{89}$ AGS. CJH, leg. 460, exp. 7. Doctrina recogida también, y de manera explícita, en la cláusula decimoséptima del asiento. AMT, sig. 6420, fol. 39r-v. 
de manera autónoma. En el resto de asuntos predominó la noción de equilibrio, dado que la Monarquía logró alejar la recurrente aspiración morisca de ver autorizado el regreso de la nación a Granada, pero, a cambio, tuvo que mostrarse más condescendiente con otras reivindicaciones de la minoría tales como el asunto de la lista o la exención del servicio militar. No en vano, "el dinero hace lo malo bueno".

\section{Bibliografía}

Aranda Doncel, Juan, "Potencial económico de la población morisca en Córdoba", Boletín de la Real Academia de Córdoba, 92 (1972), pp. 127-152.

Aranda Doncel, Juan, Los moriscos en tierras de Córdoba, Córdoba, Publicaciones del Monte de Piedad y Caja de Ahorros de Córdoba, 1984.

Bravo Caro, Juan Jesús, "Un impuesto de desterrados. El servicio de los naturales del Reino de Granada", en Estudios modernistas sobre el reino de Granada. Homenaje al Dr. D. Joaquín Gil Sanjuán, Málaga, Universidad de Málaga, 2003, pp. 45-81.

Castillo Fernández, Javier y Muñoz Buendía, Antonio “La Hacienda", en M. Barrios Aguilera (ed.), Historia del Reino de Granada. Vol. II. La época morisca y la repoblación (1502-1630), Granada, Universidad de Granada, 2000, pp. 101-177.

Domínguez Ortiz, Antonio y Vincent, Bernard, Historia de los moriscos. Vida y tragedia de una minoría, (3ª reimp.), Madrid, Alianza Editorial, 1997.

Fernández Chaves, Manuel F., "Identidad y fiscalidad: los gazis de Sevilla ante el pago del Servicio Morisco de 1597", Al-Qantara, 36/1 (2015), pp. 107-139.

Fernández Chaves, Manuel F. y Pérez García, Rafael M., En los márgenes de la Ciudad de Dios. Moriscos en Sevilla, Valencia, Publicacions de la Universitat de València/Editorial Universidad de Granada/Prensas Universitarias de Zaragoza, 2009.

Galán Sánchez, Ángel y Peinado Santaella, Rafael G., Hacienda regia y población en el Reino de Granada: la geografía morisca a comienzos del siglo XVI, Granada, Universidad de Granada, 1997.

Galán Sánchez, Ángel, "La consolidación de una fiscalidad diferencial: los servicios moriscos al inicio del reinado de Carlos V", Chrónica Nova, 31 (2005), pp. 99-146.

Galán Sánchez, Ángel, “«Herejes consentidos»: la justificación de una fiscalidad diferencial en el Reino de Granada", Historia, Instituciones, Documentos, 33 (2006), pp. 173-209.

Galán Sánchez, Ángel, "El dinero del rey y la «ley de la comunidad». Pacto político y contrato fiscal en el Reino de Granada tras la conquista" en F. Foronda (coord.), Avant le contrat social. Le contrat politique dans 
l'Occident médiéval XIII $-X V^{e}$ siècle, París, Publicatións de la Sorbonne, 2011, pp. 653-683.

García Ruipérez, Mariano, "La expulsión de los moriscos del Reino de Granada en los documentos municipales. Estudio archivístico", Documenta \& Instrumenta, 12 (2014), pp. 61-93.

García López, Aurelio, Moriscos en tierras de Uceda y Guadalajara, Guadalajara, Excma. Diputación de Guadalajara, 1992.

García López, Aurelio, “Conflictividad y conciencia. La aplicación de justicia y la minoría morisca en el reino de Castilla", en A. Mestre Sanchís y E. Giménez López (eds.), Disidencias y exilios en la España moderna. Actas de la IV Reunión Científica de la Asociación Española de Historia Moderna, Alicante, Universidad de Alicante-FEHM, 1997, pp. 455-468.

García López, Aurelio, Señores, seda y marginados. La comunidad morisca en Pastrana, Guadalajara, Ediciones Bornova, 2009.

García Pedraza, Amalia "Los cogedores de los servicios moriscos del reino de Granada”, en Á. Galán Sánchez y E. García Fernández (coords.), En busca de Zaqueo: los recaudadores de impuestos en las épocas medieval y moderna, Madrid, Instituto de Estudios Fiscales, 2012, pp. 137-158.

Halperin Donghi, Tulio, Un conflicto nacional. Moriscos y cristianos viejos en Valencia Valencia, Publicacions de la Universitat de València/Editorial Universidad de Granada/Prensas Universitarias de Zaragoza, 2008 (1 ${ }^{\mathrm{a}}$ ed. 1980),

Lapeyre, Henri, Géographie de l'Espagne morisque, París, SEVPEN, 1956.

Magán García, Juan M. y Sánchez González, Ramón, Moriscos granadinos en La Sagra de Toledo (1570-1610), Toledo, Caja de Castilla-La Mancha, 1993.

Moreno Díaz del Campo, Francisco Javier, Los moriscos de La Mancha. Sociedad, economía y modos de vida de una minoría en la Castilla moderna, Madrid, CSIC, 2009.

Moreno Díaz del Campo, Francisco Javier, “Aproximación a las fuentes para el estudio de la fiscalidad morisca: el ejemplo de La Mancha", en Hacienda y Fiscalidad. Actas de las VIII Jornadas de Castilla-La Mancha sobre investigación en archivos, Guadalajara, ANABAD CLM/Asociación de Amigos del AHP Gu, 2009.

Muñoz i Altabert, M. ${ }^{\text {a }}$ Lluïsa, "El servi de 1602: una contribució extraordinària del Regne de València a la Monarquía”, Pedralbes, 13/1 (1993), pp. 125-136.

Muñoz i Altabert, M. ${ }^{a}$ Lluïsa, Les Corts valencianes de Felipe III, Valencia, Publicacions de la Universitat de València, 2005.

Otero Mondéjar, Santiago, "«Que siendo yo cristiano viejo, la justicia procedió contra mí...». La instrumentalización de la imagen del morisco", Historia y Genealogía, 1 (2011), pp. 113-131.

Pérez García, Rafael M. y Fernández Chaves, Manuel F., "Los hermanos Berrio: capital morisco, medicación política y transformaciones comunitarias", Sharq al-Andalus, 20 (2011-2013), pp. 385-439. 
Pérez García, Rafael M. y Fernández Chaves, Manuel F., Las élites moriscas entre Granada y el Reino de Sevilla, Sevilla, Editorial Universidad de Sevilla, 2015. Pérez García, Rafael M. y Fernández Chaves, Manuel F., "La gestión de la fiscalidad como medio de ascenso social en el seno de la comunidad morisca granadina, 1502-1610", Historia, Instituciones, Documentos, 42 (2015), pp. 297-340.

Tapia Sánchez, Serafín de, La comunidad morisca de Ávila, Salamanca, Universidad de Salamanca-Excma. Diputación de Ávila, 1991.

Ulloa, Modesto, La Hacienda Real de Castilla en el reinado de Felipe II, Roma, Librería Sforzini, 1963.

Vincent, Bernard, "Las rentas particulares del reino de Granada en el siglo XVI: fardas. habices, hagüela”, en Andalucía en la Edad Moderna: economía y sociedad, Granada, Excelentísima Diputación de Granada, 1985, pp. 80-122.

Vincent, Bernard, "Los moriscos granadinos y la monarquía (1570-1609)", en J. I. Fortea y J. E. Gelabert (eds.), Ciudades en conflicto (siglos XVI-XVIII), Valladolid, Junta de Castilla y León/Marcial Pons Historia, 2008.

Vincent, Bernard, "Les frères Berrio, marchands morisques grenadins", en R. Franch Benavent y R. Benítez Sánchez-Blanco (eds.), Estudios de Historia Moderna en Homenaje a la profesora Emilia Salvador Esteban, Valencia, Universitat de València, 2008, vol. II, pp. 923-926.

Recibido: $25 / 10 / 2015$

Aceptado: 19/09/2016 